\title{
Relationships Between Segregated Afferents and Postsynaptic Neurons in the Optic Tectum of Three-Eyed Frogs
}

\author{
Lawrence C. Katz ${ }^{1}$ and Martha Constantine-Paton ${ }^{2}$ \\ 'Laboratory of Neurobiology, The Rockefeller University, New York, New York 10021, and 2Department of Biology, Kline \\ Biology Tower, Yale University, New Haven, Connecticut 06511
}

In 3-eyed frogs, afferents from 2 eyes converge on an optic tectum that normally receives input from only 1 eye. This produces an interdigitating series of stripes, resembling the ocular dominance columns in cats and monkeys. The consequences of this induced striping on the behavior of tectal dendrites was investigated in an in vitro preparation of the tectum. Stripes were labeled by anterograde transport of a fluorescent dye (rhodamine) and postsynaptic tectal cells labeled by intracellular injections of Lucifer yellow.

The same types of cells were present in both normal and striped tecta, but dendritic arbors were altered in 2 ways. In normal tecta, dendrites were most frequently biased in a rostral direction. In striped tecta, dendrites were more frequently unbiased: fewer arbors had a strong rostral bias. The second effect of stripes was on the behaviors of individual dendrites of certain cell types. Some cells, primarily those with small, highly branched arbors, had dendrites that abruptly terminated at the borders between stripes. Other cells, with larger arbors, maintained "clumps" of dendrites in both eye's stripes. While these cells had portions of their dendritic arbor in more than one stripe, each individual dendrite was restricted to a single stripe. However, the processes of many cells, especially those with extensive, medial-laterally oriented dendrites, did not respect stripe boundaries in any obvious fashion.

At the border between 2 stripes, there is an abrupt discontinuity in the patterns of activity in afferent axons. The dendritic alterations seen in striped tecta suggest that correlated activity can, in some cells, modulate the spatial arrangement of dendrites, such that an individual dendrite preferentially arborizes within such areas, but not between them. These cells as a whole can accommodate uncorrelated inputs, if these are segregated onto separate dendrites. This implies that local interactions between presynaptic terminals and postsynaptic dendrites, rather than action potentials in the postsynaptic cells, may furnish important signals for the modulation of dendritic arbor shape.

\footnotetext{
Received June 16, 1987; revised Dec. 15, 1987; accepted Dec. 23, 1987.

We wish to thank Dr. T. Wiesel for his material and intellectual support of this work. Wc arc also gratcful to H. Cline, E. Debski, D. Iarovici, and J. Naegele for their helpful comments on the manuscript, and P. Peirce for his expert photographic assistance. L.C.K. is a Lucille P. Markey Scholar, and this work was supported in part by a grant from the L. P. Markey Charitable Trust. Also supported by NIH Grants F32 EY05739 (L.C.K.) and EY 06039 (M. C-P.).

Correspondence should be addressed to Lawrence C. Katz, Neurobiology Laboratory, The Rockefeller I University, 1230 York Avenue, New York, NY 10021. Copyright $(1988$ Society for Neuroscience $0270-6474 / 88 / 093160-21 \$ 02.00 / 0$
}

In the mammalian visual cortex and the vertebrate optic tectum, segregated patterns of afferent termination, in the form of ocular dominance stripes, arise as a consequence of activity in afferent axons (Shatz and Stryker, 1978; LaVay et al., 1980; Meyer, 1982; Boss and Schmidt, 1984; Reh and Constantine-Paton, 1985; Stryker and Harris, 1986). Activity-dependent changes in the distribuion of afferent terminals have been intensively studied, as has the adult morphology of postsynaptic neurons. However, little attention has been focused on the relationship between postsynaptic dendritic morphology and the segregated pattern of afferents. Several models of column or stripe formation invoke functional interactions between pre- and postsynaptic neurons (Von der Malsburg and Willshaw, 1976; Fraser, 1980; Swindale, 1980; Whiteclaw and Cowan, 1981; Miller et al., 1986). However, such models cannot be tested without some knowledge of the structural relationships between the pre- and postsynaptic elements.

The frog optic tectum is especially suitable for examining the relationship between specific afferent axons and patterns of dendritic arborization in their target neurons. In frogs, tecta that receive inputs from 2 eyes throughout development can be produced experimentally by adding a third eye primordium during embryonic stages. The afferents from the 2 eyes segregate within the tectum and form alternating bands or stripes that resemble the pattern of normal ocular dominance columns in cats and primates (Constantine-Paton and Law, 1978; Law and Constantine-Paton, 1981).

In order to compare the morphologies of normal tectal neurons with those found in tecta receiving input from a third eye ("striped tecta"), we combined 2 fluorescent staining techniques to visualize both tectal stripes and the detailed morphology of individual tectal neurons. The dendrites of some types of tectal cells appeared to respond to stripe boundaries, as evidenced by marked changes in direction or by termination at stripe borders. No tectal neuron type showed a dendritic morphology that could explain either the stereotyped orientation or periodicity of the segregated afferents. Instead our data suggest that local interactions between afferents and restricted portions of the postsynaptic dendritic arbor play critical roles in producing the patterning of a segregated, topographically organized cortex. Some of these results have appeared in abstract form (Katz and Constantine-Paton, 1985).

\section{Materials and Methods}

Experiments involved 413 -eyed Rana pipiens tadpoles and early postmetamorphic frogs. Twenty animals were used to develop the techniques of anterograde labeling with rhodamine, intracellular recording, and staining of optic tecta in vitro, and analysis of filled neurons in flattened 

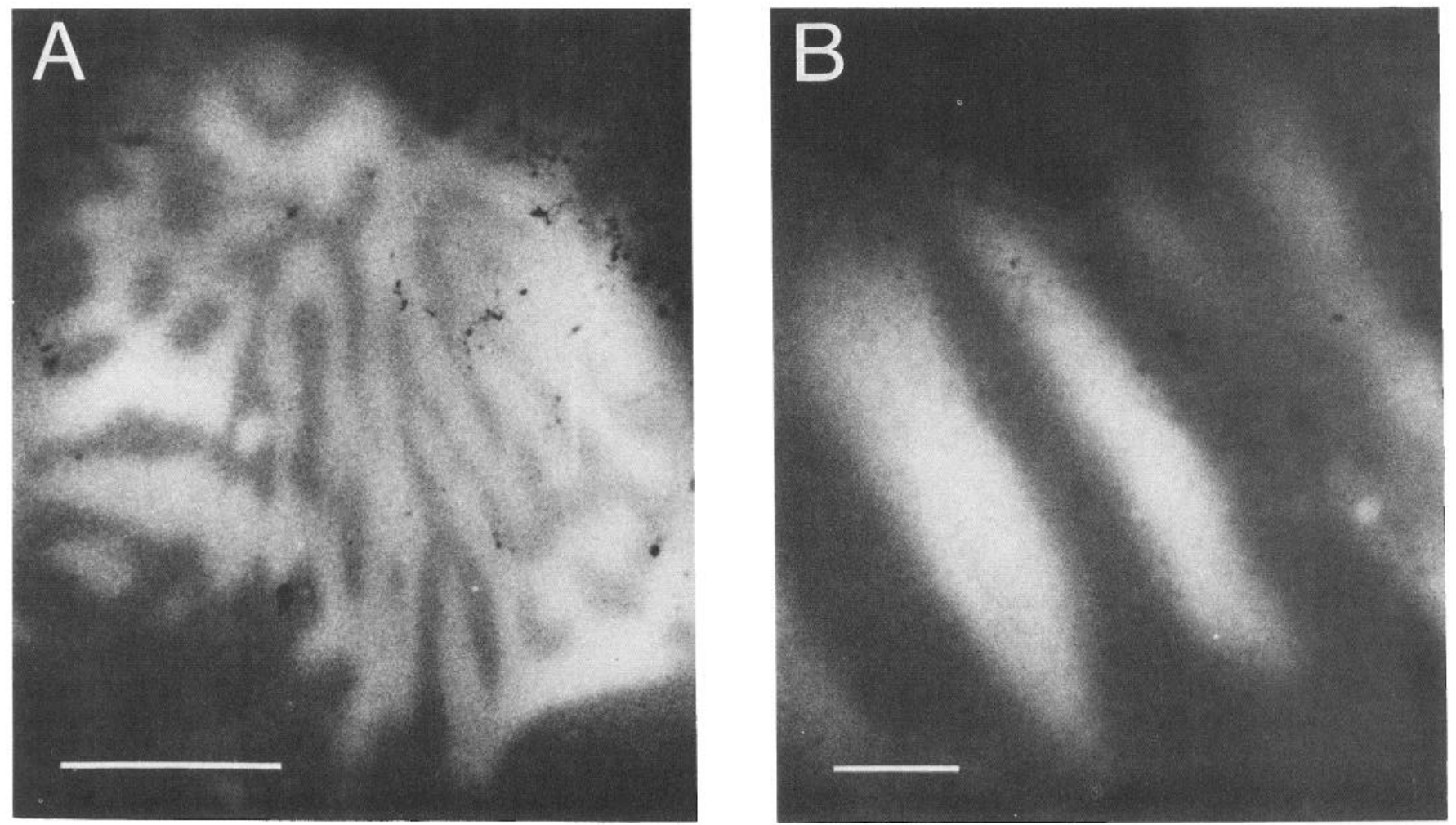

Figure 1. Rhodamine-labeled stripes in 3-eyed optic tecta in vitro. A, Dorsal view of the tectum of an early postmetamorphic frog, viewed under rhodamine excitation. Three days prior to removing the tectum, the frog's supernumerary eye was injected with $5 \%$ tetramethylrhodamine isothiocyanate. The stripes are visible as bright bands alternating with unlabeled dark bands representing terminals from the other eye. Rostral is towards the top, medial to the left. Scale bar, $1 \mathrm{~mm}$. B. Higher-power view of stripes in a younger animal (stage 54 tadpole). Same conventions as in $A$. Scale bar, $100 \mu \mathrm{m}$.

wholemounts. Stained cells from 21 animals formed the basis of our analyses.

The 3-eyed frogs were prepared as described previously (Law and Constantine-Paton, 1981). Two to four days prior to the intracellular recording session, approximately $1.0 \mu \mathrm{l}$ of $5 \%$ tetramethylrhodamine isothiocyanate (TRITC, Sigma) in 100\% DMSO was injected (under MS-222 anesthesia) into the anterior chamber of 1 eye via a glass micropipette attached to a $1 \mu \mathrm{ml}$ Hamilton syringe (Thanos and Bonhoeffer, 1983). On the day of the recording session, animals were again anesthetized with MS-222, the brain was removed and placed in icecold oxygenated frog artificial cerebrospinal fluid (ACSF; composed of $\mathrm{NaCl}, 100 \mathrm{~mm} ; \mathrm{KCl}, 2 \mathrm{~mm} ; \mathrm{CaCl}_{2}, 3 \mathrm{~mm} ; \mathrm{MgCl}_{2}, 1 \mathrm{~mm}$; glucose, 10 $\mathrm{mm}$; HEPES, $5 \mathrm{~mm}, \mathrm{pH}$ 7.4). The tecta were individually dissected free of the rest of the brain and the pigmented pia was removed. Small cuts were placed at the rostral and caudal poles in order to facilitate flattening the tecta. The tecta were placed on small pieces of embedding bag paper in a modified hippocampal slice chamber, where they were maintained at the oxygen/ACSF interface, at $15^{\circ} \mathrm{C}$.

The techniques for visualizing stripes in vitro and for intracellularly staining cells in known positions were essentially identical to those described in Katz (1987). Briefly, individual tecta were transferred from the maintenance chamber to a small chamber on the stage of an epifluorescence-equipped compound microscope. This chamber was at room temperature and perfused with both oxygen and ACSF. With a $10 \times$ objective (Wild Fluotar, NA 0.45 ), the stripes were clearly visible in living tissue. Lucifer yellow-filled microelectrodes, with tips bent about $90^{\circ}$ to facilitate penetrations normal to the tissue surface, were directed to specific regions of the stripes (i.e., borders or centers). Electrodes had resistances of $250-400 \mathrm{M} \Omega$ when filled with $20 \%$ Lucifer yellow in 0.1 $\mathrm{M} \mathrm{LiCl}$. Intracellular impalements were recognized by sudden shifts in potential and the presence of synaptic or action potentials. Because of the small size of many tectal cells (approx. $5 \mu \mathrm{m}$ ), the quality of impalements was variable. We obtained excellent dye fills even when action potentials had amplitudes of less than $10 \mathrm{mV}$. No differences were evident in the health of neurons in normal versus striped tecta, although in neither case were impalements as stable or responses as robust as those obtained in mammalian tissue with similar techniques (Katz, 1987). This is probably because of the small size of most tectal neurons and the fragility of this young tissue. In the best cases we impaled cells with $30-45 \mathrm{mV}$ action potentials. Cells were filled by passing pulses of negative current $(0.5-1 \mathrm{nA})$ for 1-7 min.

Occasionally, impaled cells lacked either spontaneous or evoked action potentials; these were usually not filled with dye. The few "inactive" cells filled exhibited a dense meshwork of branches quite distinct from any of the definitive neurons. They probably were examples of glial cells whose somata are localized in the superficial tectal laminae (Currie and Cowan, 1974).

After 3-10 cells were filled, the tectum was fixed by immersion in $4 \%$ paraformaldehyde in $0.1 \mathrm{M}$ phosphate buffer, $\mathrm{pH} 7.4$. Tecta remained in fix from $1 \mathrm{~d}$ to 1 month. After fixation, the tecta were removed from the paper supports, dehydrated through graded alcohols, and cleared in xylene. They were then placed on a slide and coverslipped using Krystalon (Harleco).

Cells were analyzed using 2- and 3-dimensional drawings of their dendritic arbors, measurements of dendritic length, and measurements of the area encompassed by different portions of the dendritic arbor. Two-dimensional drawings were made under epifluorescence illumination on a Zeiss WL microscope, with a camera lucida attachment, using $63 \times$ or $100 \times$ oil-immersion objectives (n.a. 1.3 and 1.0, respectively). Drawings were made using black paper and white pencils. Some cells were reconstructed in 3 dimensions using the computer microscope system described by Gilbert and Wiesel (1983). This system was also used to calculate the dendritic length and areal extent. Since all our views of cells were tangential, the 3-dimensional reconstructions allowed us to rotate cells and observe their interactions with stripes in the radial plane.

Shrinkage after fixation and processing was considerable; by measuring the width of stripes and the thicknesses of different laminae, we estimated that the tissue shrank about $75 \%$. Although this is a great deal of shrinkage, it is not surprising since (1) the tecta of tadpoles contains large amounts of extracellular space (Gaze et al., 1979; Constantine-Paton and Norden, 1986), and (2) the tissue was dehydrated 


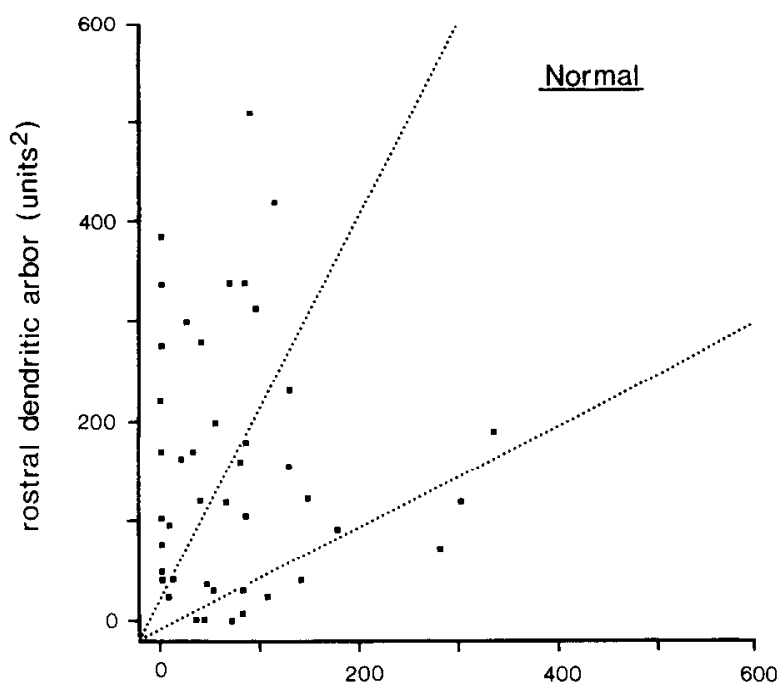

caudal dendritic arbor (units ${ }^{2}$ )

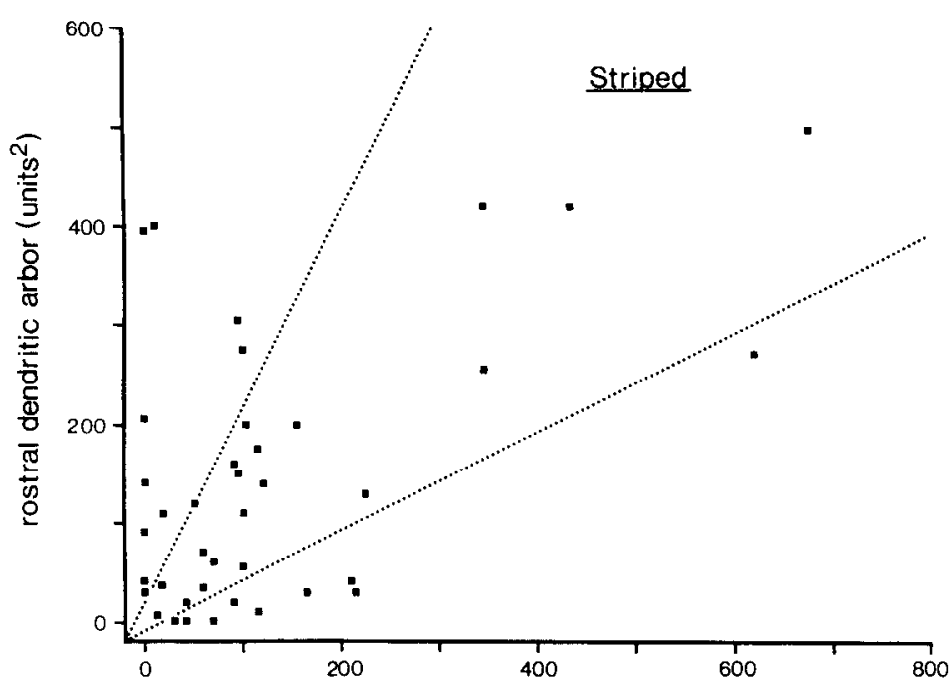

caudal dendritic arbor (units ${ }^{2}$ )

Figure 2. The rostral-caudal biases of dendritic arbors in normal and striped tecta. The lower and upper dotted lines represent rostral-caudal biases of $1: 2$ and 2:1, respectively. Each dot represents the bias ratio for one cell. Cells in the lower third of the graph were considered to be strongly caudally biased, those in the middle third relatively unbiased, and those in the upper third, strongly caudally biased. In normal tecta, many cells are rostrally biased; few are unbiased. In the striped tecta, most cells are unbiased. Figure 3 summarizes these results.

and cleared free-floating; shrinkage was therefore not prevented by anchoring the tissue to gelatin-coated slides. Since we were interested in dendritic patterns and relative, rather than absolute, sizes, no corrections were made for shrinkage. Therefore, our accounts of tangential dendritic arbor dimensions are given in terms of "stripe widths" (see Results). In unfixed tissue, a stripe width of $150-200 \mu \mathrm{m}$ is very constant across animals of all ages and sizes (Law and Constantine-Paton, 1981; Constantine-Paton and Ferrari-Eastman, 1987). In the 3-dimensional representations, the $Z$-axis was expanded to accentuate features of the radial organization.

\section{Results}

Most previous studies on the organization and modifiability of the anuran optic tectum separately used Golgi or intracellular staining to analyze tectal neurons or anterograde transport techniques to reveal segregated retinotectal afferents. However, in order to visualize, in the same brain, both the pattern of afferents and their relationship to dendrites of postsynaptic neurons, it was necessary to develop staining techniques that allowed discrimination of the pre- and postsynaptic elements on the basis of different dyes.

Anterograde labeling of retinotectal axons with TRITC applied in vitro has been used previously to label individual axons (Thanos and Bonhoeffer, 1983). TRITC also worked well in vivo to label the characteristic pattern of ocular dominance stripes seen in the 3-eyed frog. Several examples of striped tecta, removed from animals previously injected intraocularly with TRITC and subsequently maintained in vitro are shown in Figure 1. Even at low power (e.g., 40×), the stripes were clearly visible, and their pattern was identical to that seen following intraocular injections of ${ }^{3} \mathrm{H}$-proline or HRP. In such preparations the stripe/interstripe boundaries were very sharp, and we could assign borders with an accuracy of $\pm 10 \mu \mathrm{m}$.

In all, 96 tectal neurons were successfully impaled, injected, and analyzed: 51 in normal tecta and 45 in striped tecta of the same or similarly staged animals. The 96 injected cells were located at various depths in the superficial half of the tecta, ranging from the dorsal half of layer 6 (Szekely and Lazar, 1976) to the pia. They represented a wide range of morphologies that generally encompassed cell types previously described using other techniques. Only one structure, the locally arborizing axon or axon collateral of tectal neurons (Lazar, 1973; Szekely and Lazar 1976) was not clearly discernible in the cells we examined. We characterized neuronal processes as dendrites based on either their origin from a secondary or higher-order dendrite or their large caliber when the process arose from the cell body or primary dendrite. Although fine axon-like processes may not have been detected in our material because of incomplete dye fills, this in unlikely since we could visualize many fine axons that did not arborize within the tectum. It is more likely that these local axon collaterals arborized within the dendritic arbor of small, deep (SD) cells, for which we did not reconstruct individual processes (see below). Alternatively or in addition, our small sample of cells in the deeper tectal laminae (deep layer 6 and below) may not have included neurons with local axons.

The stripes of retinal afferent terminals span the radial thickness of the superficial tectal layers (layers 9 and 8) but are highly segregated in the tangential domain. Since we were interested in the relationship of this tangential organization to the dendritic patterns, we grouped cells into categories based primarily on their tangential organization, rather than on the radial or laminar pattern of their dendrites. The use of flattened, unsectioned tecta greatly facilitated this examination since it allowed visualization of the entire dendritic tree of even the largest tectal neurons without the truncations necessarily produced in sectioned material. In contrast, most previous studies have emphasized radial organization of tectal dendrites in sectioned material and classified cells accordingly (e.g., Potter, 1969; Lazar, 1973; Szekely and Lazar, 1976; Antal et al., 1986; Matsumoto et al., 1986). As a result of this difference in approach, our assignments are not directly comparable to those used for tectal neurons in previous studies. In some cases the similarities are clear and will be pointed out when appropriate. 
Table 1. Cell types in normal and striped tecta

Percentage cell type

\begin{tabular}{lccccccc}
\cline { 2 - 7 } Tecta & SD & SS & SSC & LG & SG & ML & RC \\
\hline Normal & 27 & 10 & 2 & 10 & 27 & 8 & 15 \\
& $(14)$ & $(5)$ & $(1)$ & $(5)$ & $(14)$ & $(4)$ & $(8)$ \\
Striped & 44 & 4 & 10 & 7 & 16 & 13 & 4 \\
& $(20)$ & $(2)$ & $(5)$ & $(3)$ & $(7)$ & $(6)$ & $(2)$
\end{tabular}

The number and percent of cells of various categories encountered in normal and striped tecta. Numbers in parentheses are the actual number of each type. SD, small, deep cells; SS, small, superficial cells; SSC, small, superficial, clumped cells; LG, large ganglionic cells; SG, small ganglionic cells; $\mathrm{ML}$, medial-laterally oriented cells; RC, rostral-caudally biased cells.

\section{Dendrites in normal tecta have a pronounced rostral bias}

In most experiments, we filled 4-8 cclls in each tectum. Lowpower microscopic examination of these cells in normal tecta revealed an unexpected bias in the tangential organization of the dendritic arbor. Cells frequently had a larger proportion of their dendritic arbor elaborated in the region rostral to, rather than caudal to, their cell bodies. No bias was apparent along the medial-lateral axis. We quantified this impression by the following technique. The dendritic arbor was divided into a rostral and caudal portion by drawing a medial-lateral line through the cell body. The area encompassed by the rostral and caudal portions of the dendritic fields were then measured using a digitizing pad connected to a computer.

The results (Fig. 2) indicate a pronounced rostral bias in dendritic coverage, which is true for cells in all morphological categories and at all positions in the tectum. We considered cells to be strongly rostrally biased if the ratio of rostral to caudal dendritic coverage was greater than or equal to 2 , rclativcly unbiased if the ratio fell between 2 and 0.5 , and strongly caudally biased if less than or equal to 0.5 . Figure 3 shows the relative numbers of cells in each category. About $55 \%$ of cells were strongly rostrally biased, $20 \%$ were biased in the opposite (caudal) direction, and $25 \%$ were unbiased.

This distribution was markedly altered in striped tecta. As Figures 2 and 3 illustrate, these tecta contained considerably more cells with unbiased dendrites. Compared with normal tecta, striped tecta contained fewer rostrally biased cells, more unbiased cells, and roughly equal numbers of caudally biased cells.

\section{Response of tectal cell dendrites to stripes}

\section{Cell classification}

Cells were grouped into 7 categories, based on the orientation of their dendrites, the size and general appearance of the arbor, and the relative depth of the soma. The criteria used for assigning cells to each category are detailed below; Table 1 shows the numbers of cells in each category.

This study was undertaken with 2 general questions in mind. First, we inquired whether there existed cells in normal or striped tecta whose shape could serve as a scaffolding for the pattern of tcctal stripes. Our second question was whether the pattern of induced stripes could alter or define the morphology of postsynaptic neurons. The answer to the first question is clear: no tectal neuron type was encountered in either normal or striped tecta with a dendritic morphology that consistently matched either the diameter or periodicity of the eye-specific stripes. The

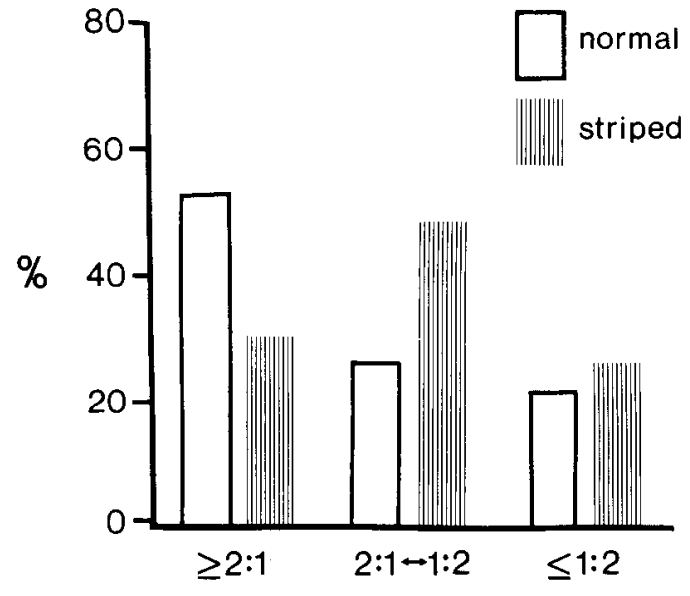

\section{rostral : caudal ratio}

Figure 3. Relative percentages of rostrally biased ( $\geq 2: 1$ rostral-caudal ratio), unbiased (between $2: 1$ and 1:2), and caudally biased ( $\leq 1: 2)$ cells in normal and striped tecta. There is a pronounced shift from rostrally biased to unbiased cells in striped tecta; the number of caudally biased cells remains constant.

answer to the second question is more complicated. Cells that respected stripe boundaries were occasionally encountered (e.g., Fig. 4). These neurons resembled both the pyramidal (Fig. 4, $B$, $C$ ), and pear-shaped (Fig. $4 A$ ) neurons reported by earlier investigators, and accounted for about $15 \%$ of our sample. The dendrites of other cells (about 10\% of our sample), however, could cross boundaries and arborize within adjacent interstripes. Closer examination of this group revealed several subtle ways in which the postsynaptic neurons appeared to have had their dendritic patterns altered in rcsponse to stripes. In several cases the dendritic arbors of members of this group were not uniform throughout their tangential extent, with gaps located at the stripe/ interstripe boundary. In the following sections, we detail the range of responses observed in the dendrites of these and other types of cells.

\section{Small, superficial and small, superficial clumped cells}

The most obvious examples of cells confined to single stripes were cells categorized as small, superficial (SS) cells. This category, about $5 \%$ of our sample in striped tecta, and about $10 \%$ in normal animals, contained cells with small (5-7 $\mu \mathrm{m}$ diameter) cell bodies, located in the more dorsal laminae (probably layers 8 and 9). One to five primary dendrites were arranged radially around the soma; these branched repeatedly to form a dense, superficial arbor 1-2 stripe widths in diameter. Examples of these cells from striped tecta are shown in Figure 4. They probably correspond to the superficial amacrine and stellate cells of layer 9 as well as the small pyramids or pear-shaped cells seen in earlier studies (Lazar, 1973; Szekely and Lazar, 1976). In striped tecta, we observed arbors that resembled those of SS cells but that were divided into discrete clumps of branches, separated by zones of relatively dendrite-free territory. We designated these cells as small, superficial clumped (SSC) cells. SSC cells were more frequently encountered in striped than in normal tecta; we filled 5 SSC cells in striped but only one in normal tecta. SS cells were more frequent in normal than in striped tecta; 2 SS cells were seen in striped tecta versus 5 in normal.

In order to understand the "clumping" phenomena more ful- 
$3164 \mathrm{Katz}$ and Constantine-Paton - Stripes and Postsynaptic Neurons

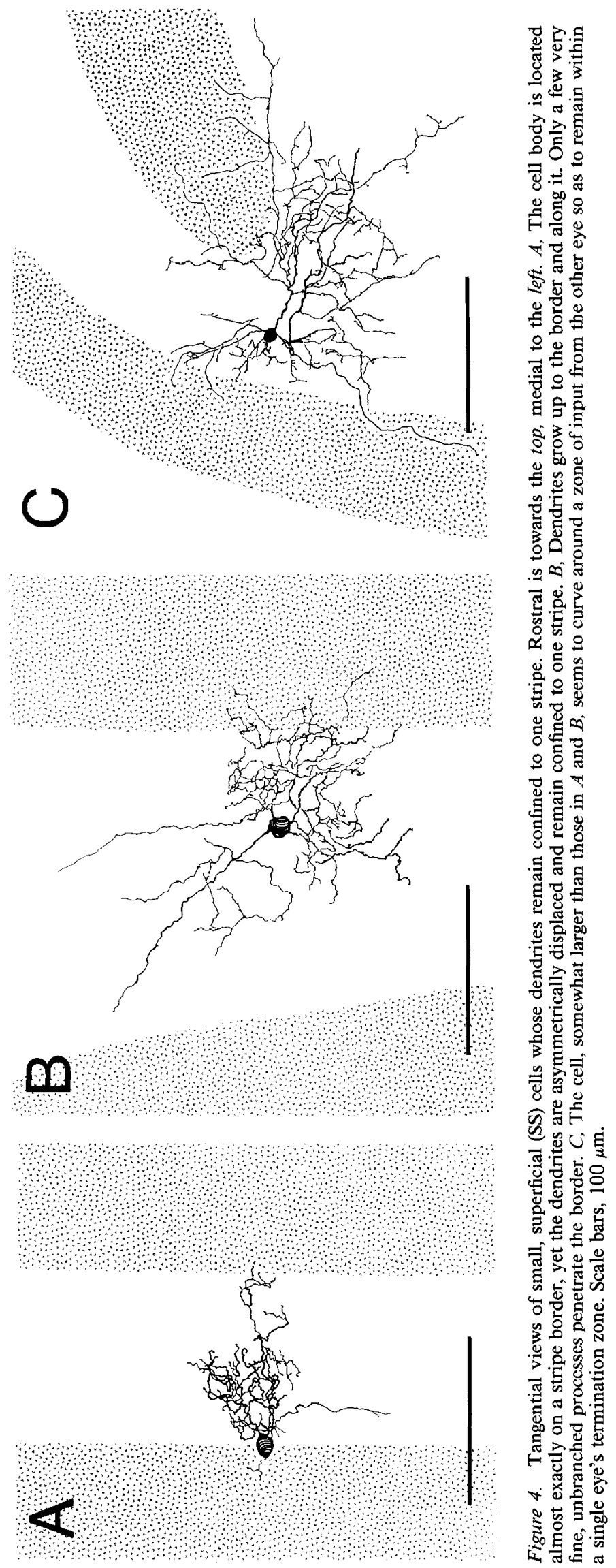



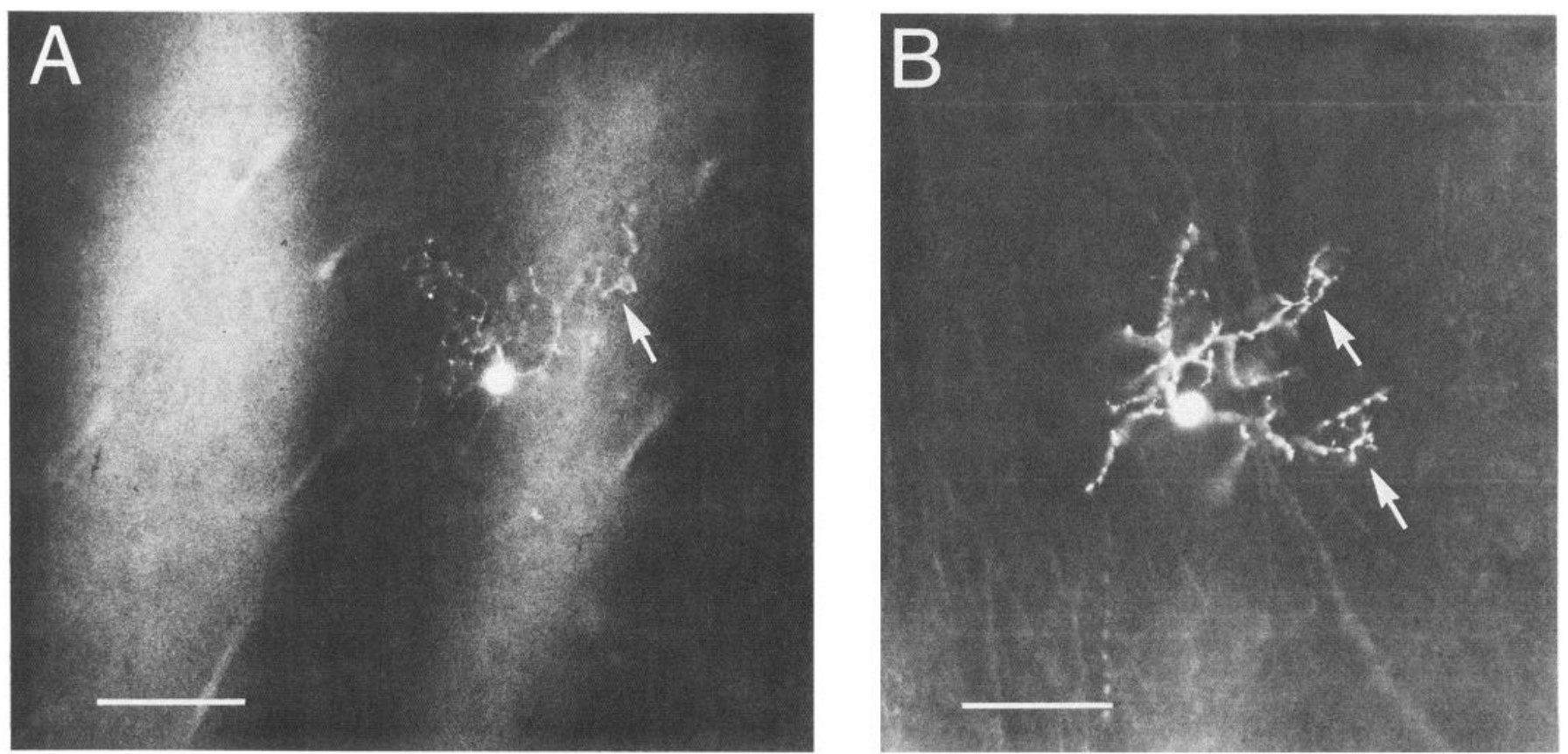

Figure 5. Tangential views of small, superficial, clumped (SSC) cells in striped tecta. These double exposures were made in vitro under rhodamine and Lucifer yellow excitation wavelengths to visualize the stripes and dendrites of these cells simultaneously. $A$, Two discrete zones of dendrites are visible, one within a labeled stripe (arrow) and one within an unlabeled stripe. $B$, The stripes are fainter, but 2 distinct clumps of dendrites are visible within an unlabeled stripe (arrows), while the rest of the cell's processes are within a labeled stripe. Scale bars, $100 \mu \mathrm{m}$.

ly, we carefully reconstructed individual primary dendrites of several of these cells and examined the relationship of each dendrite to the stripe boundaries. Two examples of this analysis are shown in Figures 7 and 8 . In both cases, it appears that after the first branch point, the subsequent arbor remains primarily within a single stripe. For example, the cell in Figure 8 was a superficial cell with an extensive dendritic arbor; however, on casual inspection the arbor did not seem related to the pattern of stripes. When the constituent dendrites were considered separately, though, all 6 secondary dendrites had more than $80 \%$ of their processes located within the same stripe or interstripe region, and 3 of the 6 had over $90 \%$ of their arbor in one region. In order to determine whether this segregation was just coincidence, we phase-shifted the actual stripe borders laterally half the width of a stripe, and remeasured the amount of dendrite in each stripe/interstripe region. After the shift, only half the dendrites had more than $80 \%$ of their arbor in one region; only one still had $90 \%$ of the arbor in one region. We did a similar analysis on the cell shown in Figure 7. Originally both secondary dendrites had over $90 \%$ of their arbors within one stripe; after the shift, one dendrite had only $58 \%$, the other $73 \%$. Although by no means conclusive, these simple tests imply that the restriction of dendrites to one stripe is not completely random.

\section{Large and small ganglionic cells}

The behavior of SSC cells suggested that all dendrites of a cell might not act in concert when faced with stripes, but that perhaps each dendrite could behave as an autonomous unit. Thus, even when the total dendritic arbor of a cell showed no overall preference for the stripes of one eye over another, the underlying elements could be segregated. Unlike the "clumped" cells, which from the outset gave the impression of some underlying segregation, the behavior of cells in other categories was variable and difficult to quantify in the presence of the abnormally pro- duced discontinuities in the afferent field, and we cannot be certain that they are related to stripes. For instance, in both normal and striped tecta we encountered a distinctive type of cell we termed large, ganglionic (LG) cells. Cells in this category had 9- to $12-\mu \mathrm{m}$-diameter somata located in the middle layers of the tectum, usually lower layer 8 , layer 7 , and occasionally upper layer 6 . Three to five primary dendrites radiated from the somata and rose gradually, arborizing throughout the superficial tectal laminae. In tangential views, the dendritic arbors were roughly circular and typically 3-6 stripe widths in diameter. These cells resemble the ganglionic (Szekely and Lazar, 1976; Antal et al., 1986; Matsumoto et al., 1986) and multipolar (Potter, 1969) cells described previously. Using cobalt-lysine and HRP backfilling techniques, Lazar et al. (1983) have shown that these are among the efferent neurons of the tectum with axons in both rostral and caudal tectal projection zones.

In tangential views, LG cells in normal and striped tecta appeared indistinguishable (Fig. 9). However, when LG cells were reconstructed in 3 dimensions and then rotated $90^{\circ}$ to give a coronal view, a different picture emerged. As the dendrites of an LG cell encountered a stripe, they sometimes made abrupt vertical turns and headed towards the pia, growing horizontally only after reaching the most superficial subpial laminae. Other dendrites first grew across borders without arborizing, then turned dorsally at either a stripe or interstripe border, and finally began branching. The behavior of 2 individual dendrites at stripe borders is shown in Figure 10. The branch in Figure $10 B$ best illustrates the kind of pattern we believe might represent a response to a boundary. The branch in Figure $10 A$ behaves similarly, but there are definitely instances of secondary branches making dorsal turns within a stripe. The borders might therefore be a stimulus for this turning behavior but are probably not the only stimulus present.

Similar phenomena were observed in a related category of cells termed small ganglionic (SG) cells. Though more hetero- 


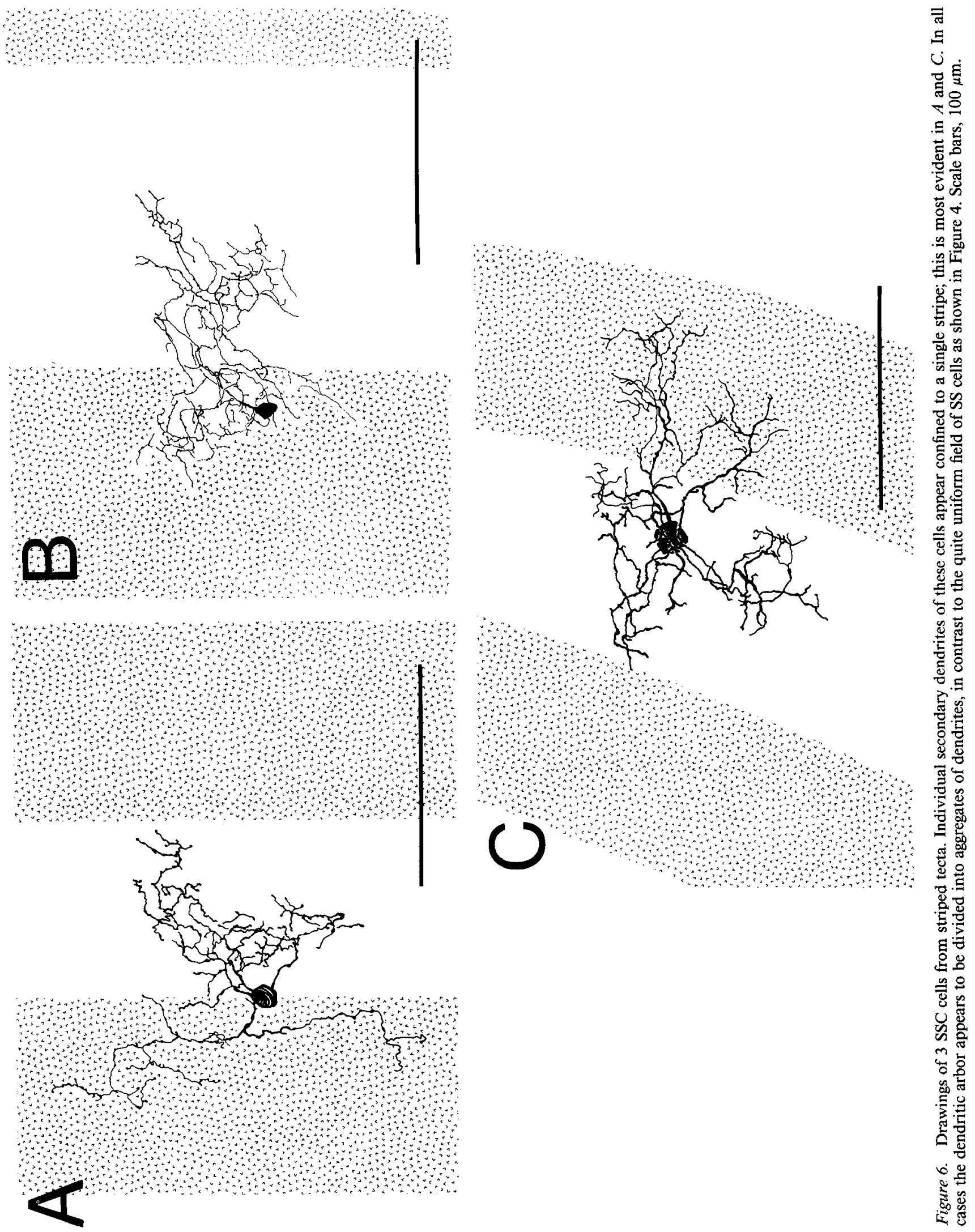




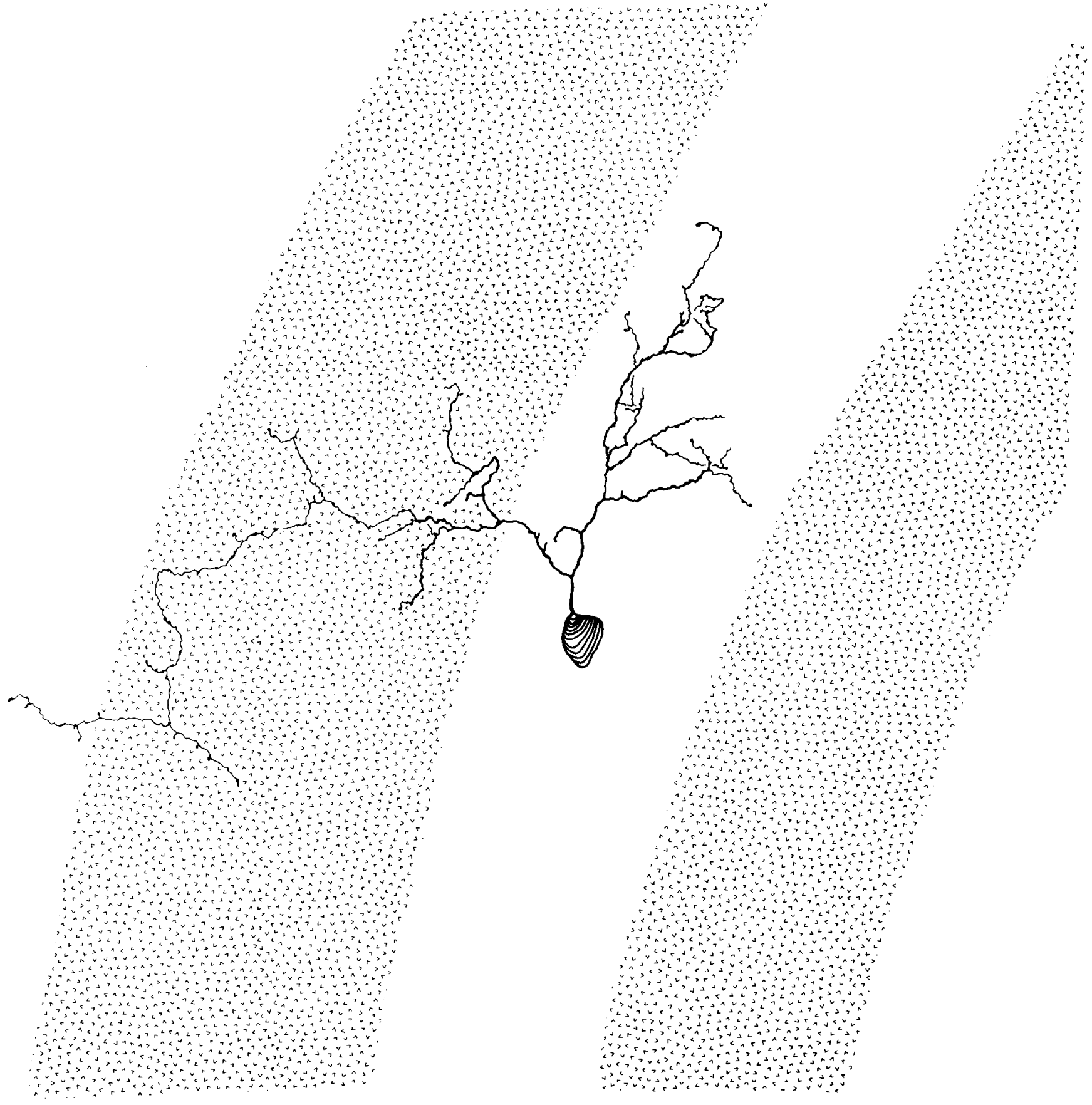

Figure 7. Reconstruction of a single primary dendrite of an SSC cell. After the first branch point, each secondary dendrite remains almost entirely confined to a single eye's stripe.

geneous than the LG category, SG cells had roughly the same dendritic tree structure and cell body position. Some of these have clearly been included in the "ganglionic" category of earlier investigators. In our material, the somata of SG cells were smaller: about 6-8 $\mu \mathrm{m}$ compared with $9-12 \mu \mathrm{m}$ in LG cells. In striped tecta, SG cells also seemed to respond to stripe boundaries by dorsal turns of dendrites. An example of one of these cells in tangential and rotated coronal views is shown in Figure 11.

\section{Small, deep cells}

The most numerous cells we encountered in both normal and striped tecta were very small, deep (SD) cells. Their 5- to 6- $\mu \mathrm{m}$ diameter cell bodies were located primarily in layer 6, a layer densely packed with cell bodies. A single dendrite arose from the soma and ascended vertically to arborize in the more dorsal layers. This category of cells encompassed a number of the categories of small pear-shaped or pyramidal neurons identified previously on the basis of the laminar organization of the dendrites, and also probably includes some cells whose axons arborize among the dendrites. However, after Lucifer yellow filling, and in tangential wholemounts, the dense network of extremely fine processes made discrimination of individual processes difficult. The dense arbors of these cells were small, usually less than half a stripe width in diameter. Often their size 

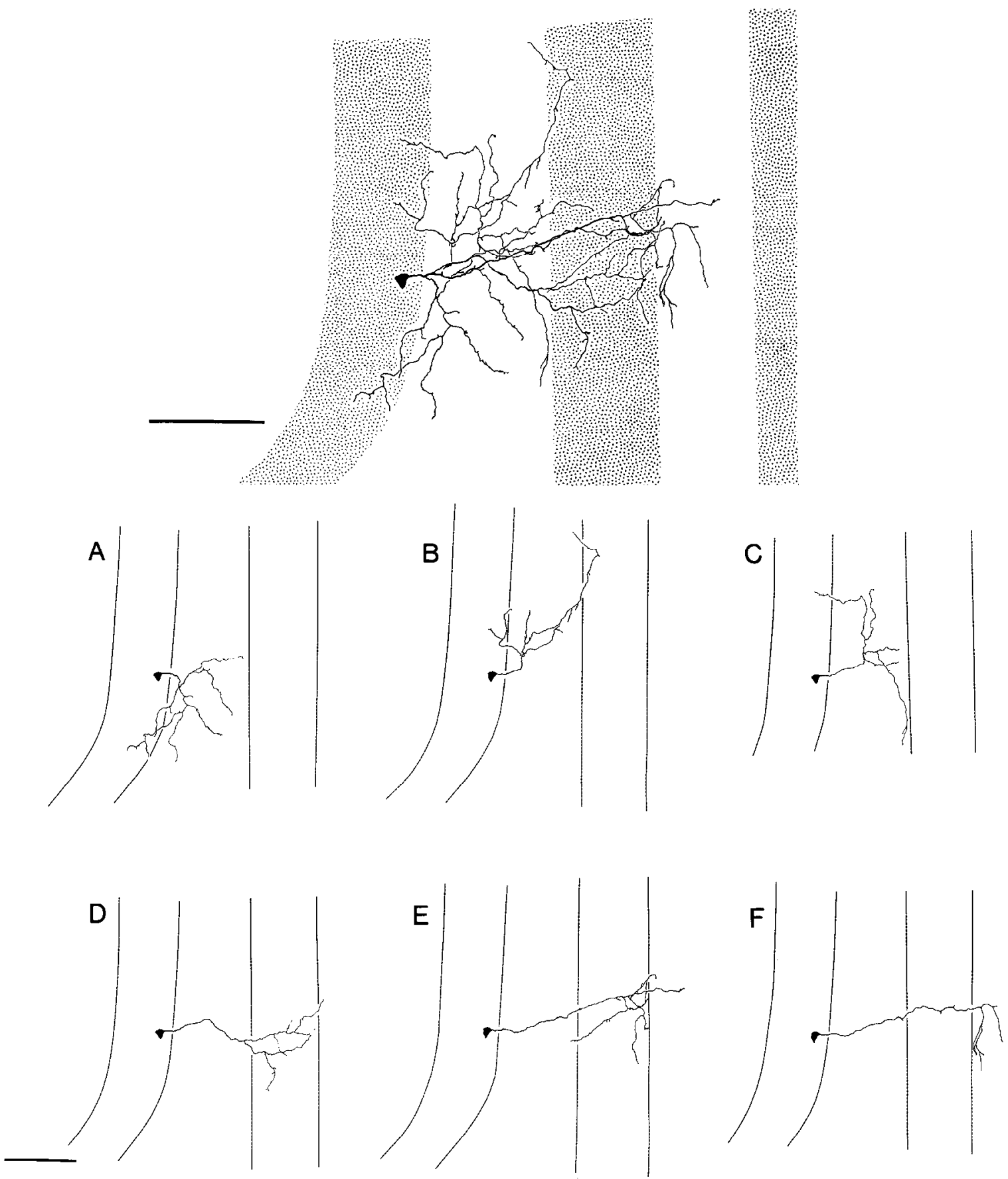

Figure 8. A second example of a cell whose secondary dendrites remain confined to a single eye's stripe. The entire cell is drawn at the top. There appears to be no restriction of the dendrites to one eye or the other. However, when each secondary dendrite is examined in isolation $(A-F)$, the restriction of an individual dendrite to a single eye's stripe becomes apparent. Scale bars, $100 \mu \mathrm{m}$.

relative to a stripe made the relationship to a stripe border irrelevant (if they were located in the middle of a stripe) or hard to discern (especially in cells whose arbors were less than $1 / 4$ the width of a stripe). However, the larger members of this group showed consistent responses to the presence of a stripe border, especially apparent in 3-dimensional reconstructions and rotations.

The convoluted and branching patterns of SD processes made accurate 2-dimensional drawings impossible. Instead, the arborization patterns were digitized using optical sectioning. Starting at the cell body, the plane of focus was incremented in 5 $\mu \mathrm{m}$ steps, and each section of a process in focus was represented by a dot. The arbor is therefore represented as a cloud of dots, which gives an accurate impression about the distribution and density of processes.

Examples of such reconstructions from normal tecta are shown in Figure 12. In the tangential plane, SD arbors were roughly elliptical and, in these examples, slightly elongated along the rostral-caudal axis. When rotated $90^{\circ}$, they appeared coneshaped, with the widest point of the arbor in the more dorsal tectal layers. In contrast, reconstructions of 4 cells near borders in striped tecta (Figs. 13,15) revealed cells whose arbors appeared markedly skewed. In these cells, the presence of a stripe/ interstripe border corresponded exactly with the boundaries of 

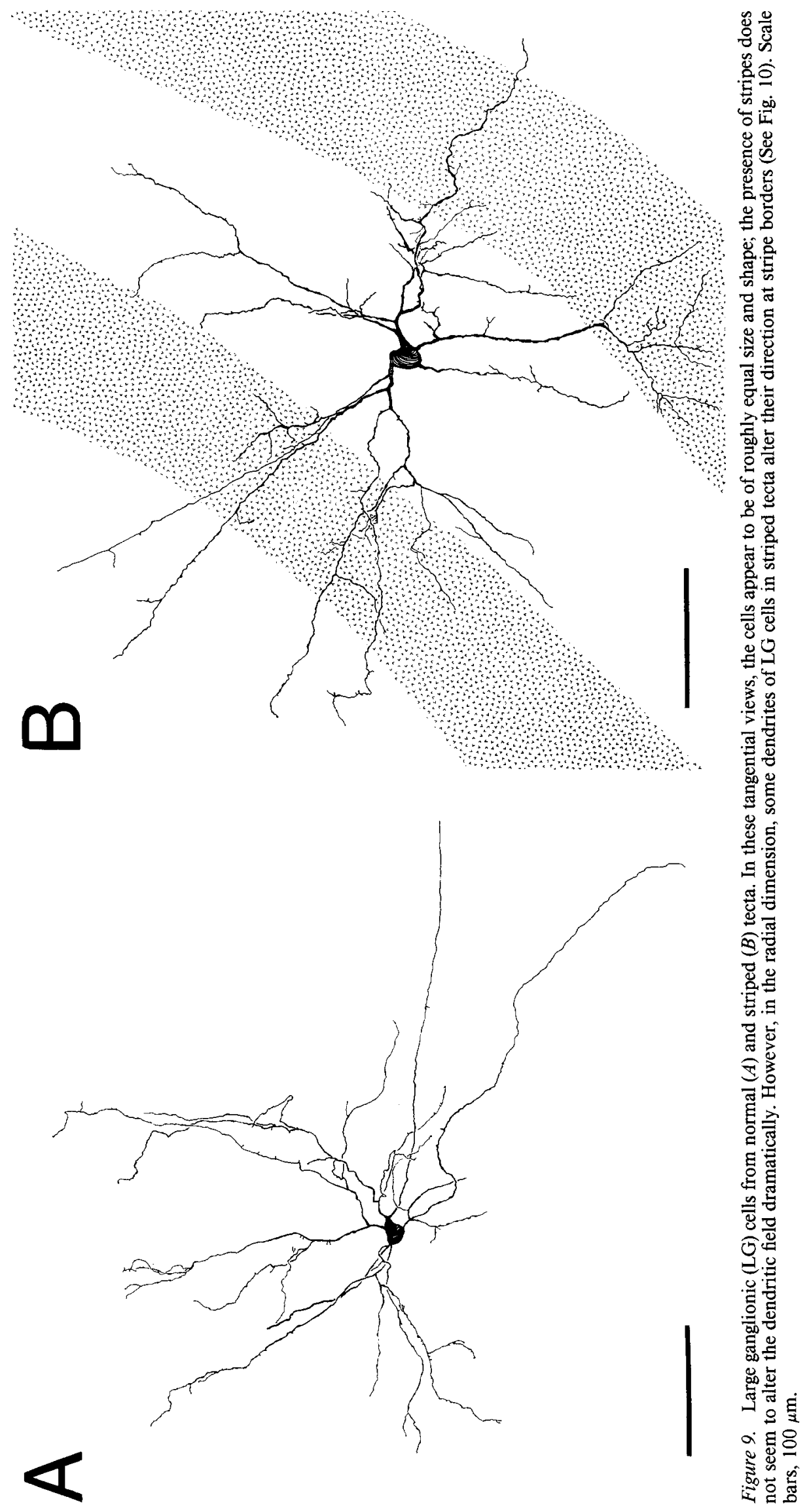

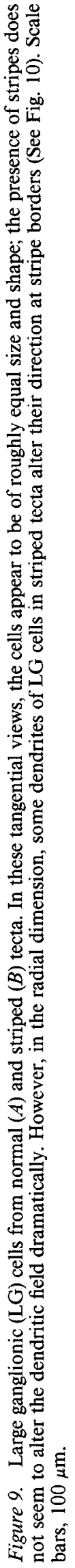




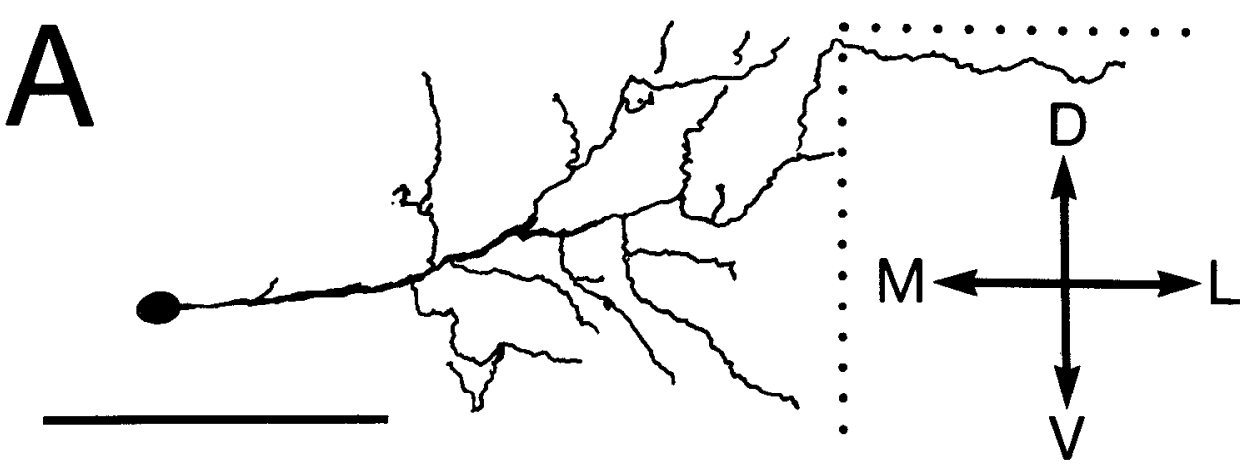

Figure 10. The behavior of 2 dendrites from the neuron in Figure $9 B$ as they approach a stripe border, as seen in a rotated, coronal view. The vertical dotted lines represent stripe borders, the horizontal dotted lines are the pial surface. As dendrites approach the border, they either terminate or extend vertically to cross into the adjacent stripe. This is particularly evident in $B$, where a primary dendrite makes an abrupt vertical turn in the immediate vicinity of a stripe border. Scale bars, $50 \mu \mathrm{m}$.

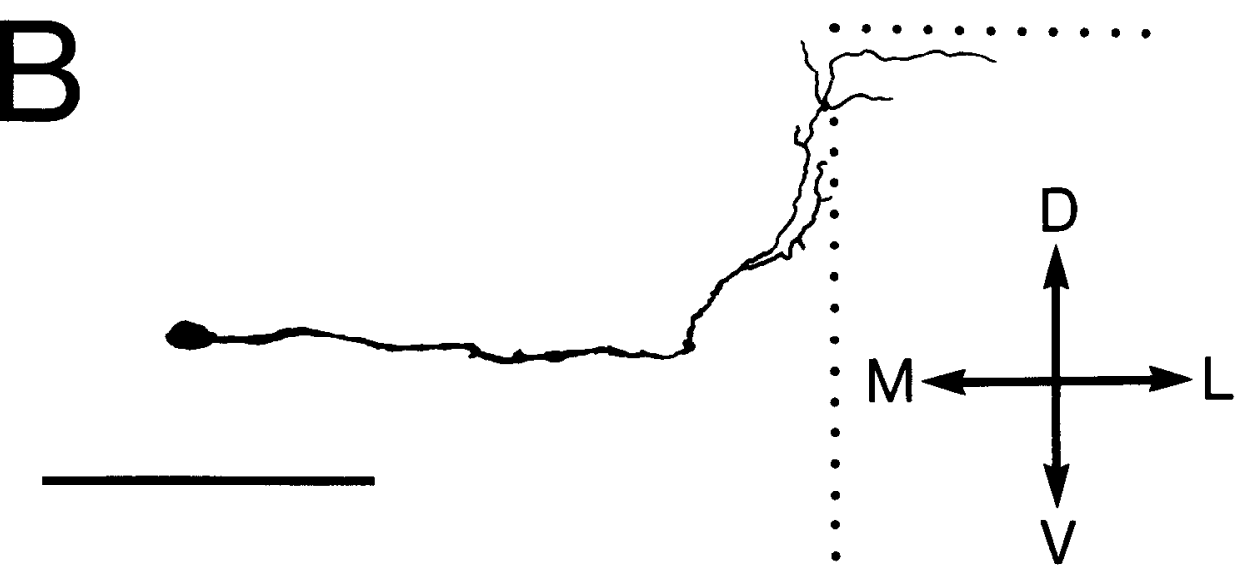

A<smiles>[M]C(I)(I)C(I)I</smiles>
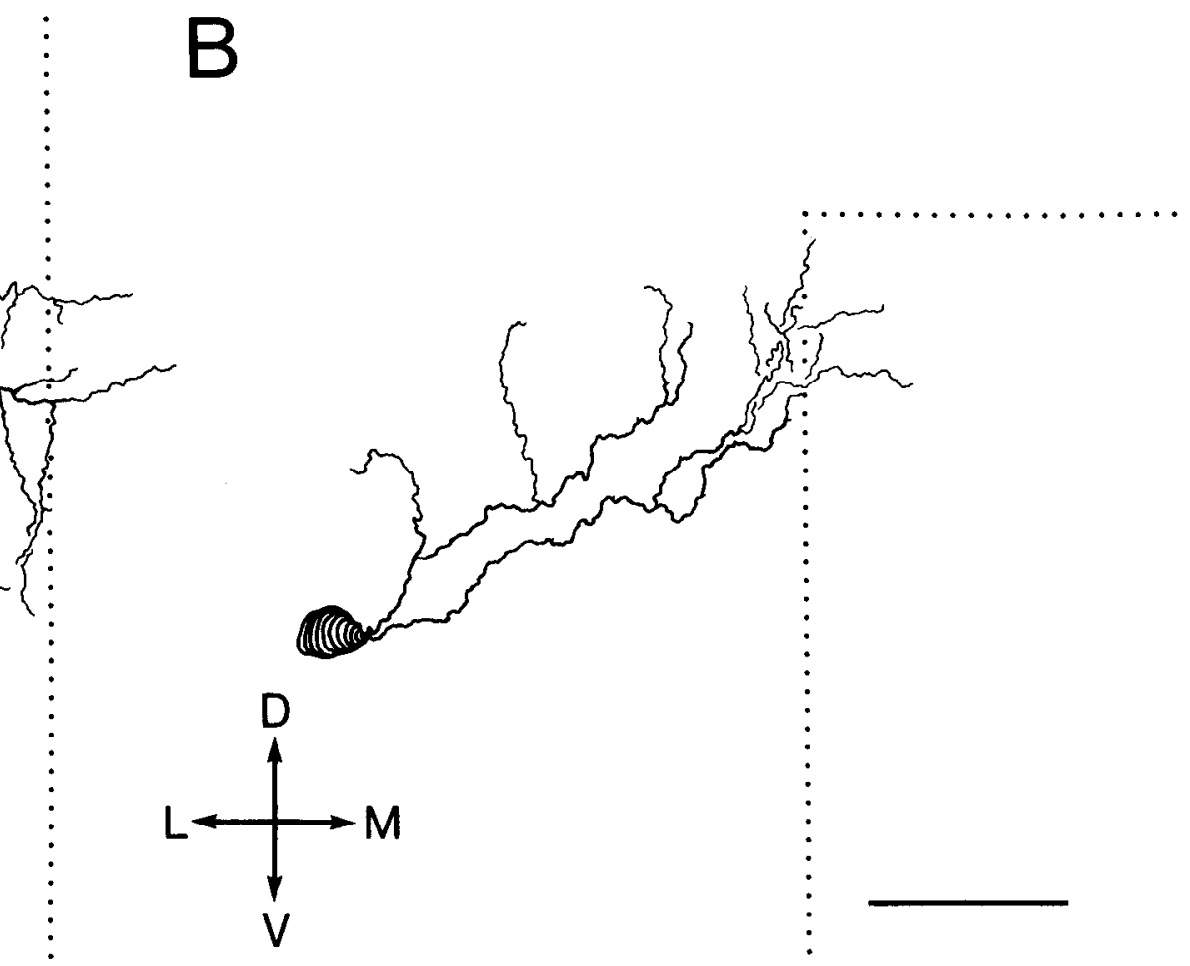

Figure 11. A portion of the dendritic arbor of a small, ganglionic (SG) cell in tangential $(A)$ and rotated coronal $(B)$ views. SG cells, like the LG cell in Figure 10, respond to stripe boundaries by directing their dendrites vertically, towards the pia. Scale bars, $50 \mu \mathrm{m}$. 
A
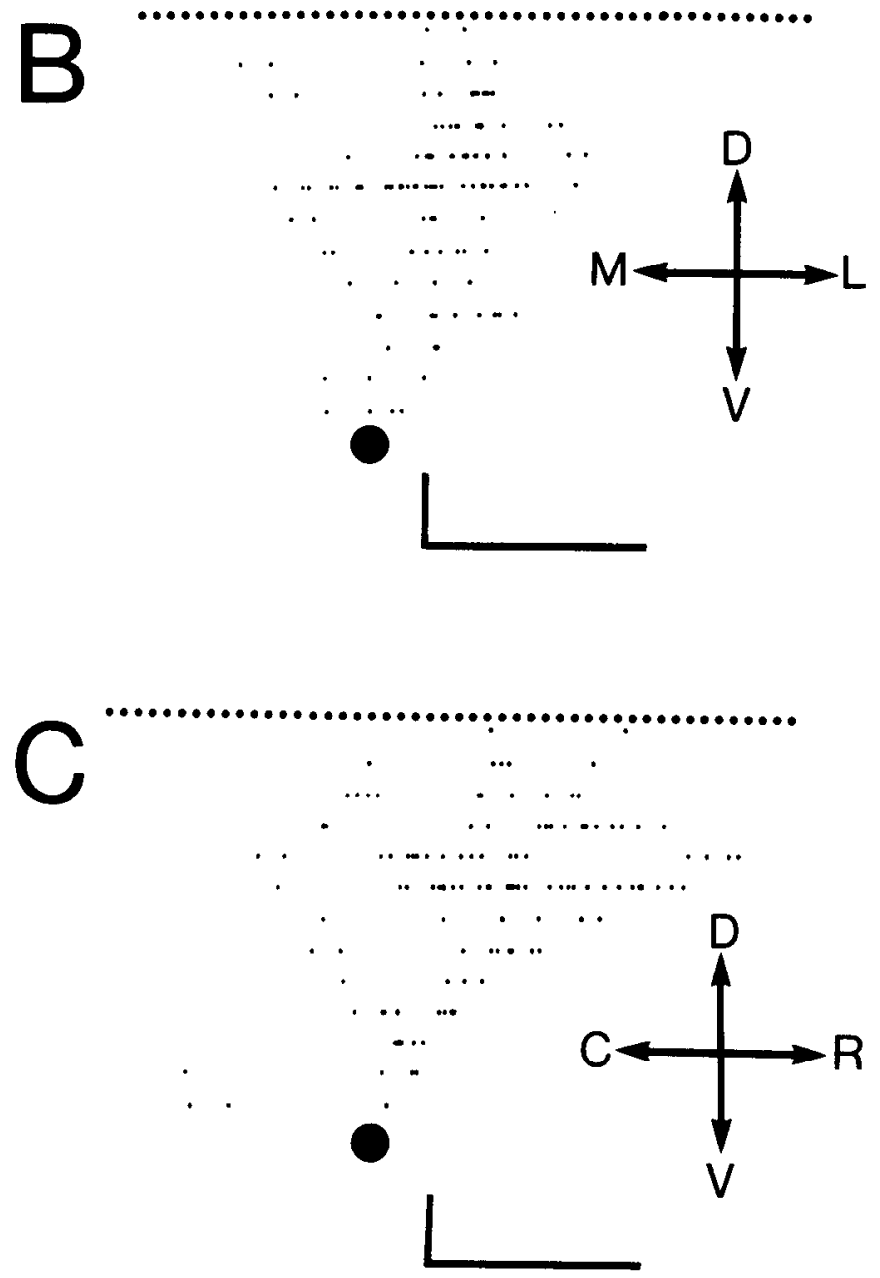

Figure 12. Dot-plot representation of a small, deep (SD) cell from a normal tectum. Each dot represents an in-focus segment of dendrite at a particular depth. The thicker dotted lines represent the pial surface; the large single dot, the cell body. $A$, Tangential view; $B$, coronal view; $C$, sagittal view. The cell has a rostral bias, but its dendritic arbor is symmetric. Contrast this cell with the one in Figure 13, from a striped tectum. Scale bars: horizontal, $50 \mu \mathrm{m}$; vcrtical, $10 \mu \mathrm{m}$.
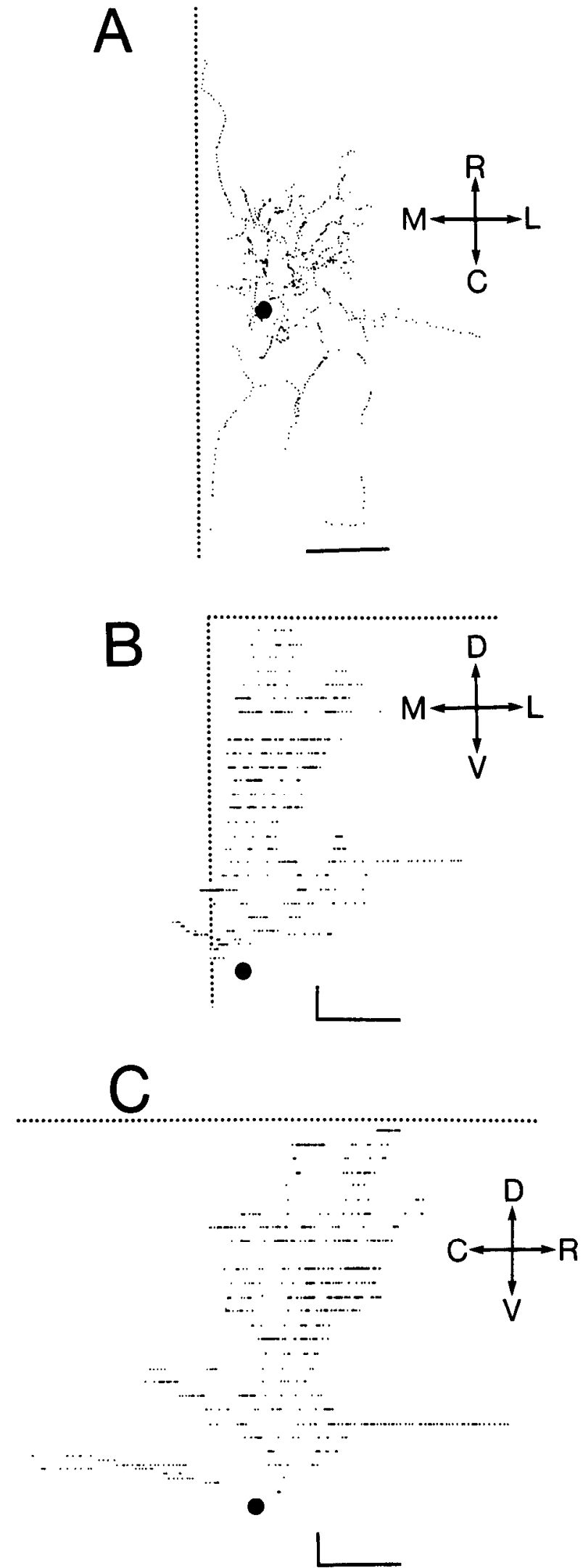

Figure 13. Dot-plot representation of an SD cell, in a striped tectum, near a stripe border. In $A$ (tangential), and $B$ (coronal) views, the stripe boundary (dotted lines) forms an apparent barrier that the cell's dendrites do not cross. Along the length of a stripe, however, there is no evidence for such restriction, as the sagittal view in $C$ shows. Scale bars: horizontal, $50 \mu \mathrm{m}$; vertical, $10 \mu \mathrm{m}$. 
A

Figure 14. Dot-plot representation of a "clumped" SD cell from a normal tectum. In the tangential view $(A)$ and coronal view $(B)$, the symmetric, larger parent arbor lies close to (less than one stripe width away from) the smaller daughter arbor. Compare this cell with the example from a striped tectum shown in Figure 15. Scale bars: horizontal, $50 \mu \mathrm{m}$; vertical, $20 \mu \mathrm{m}$.
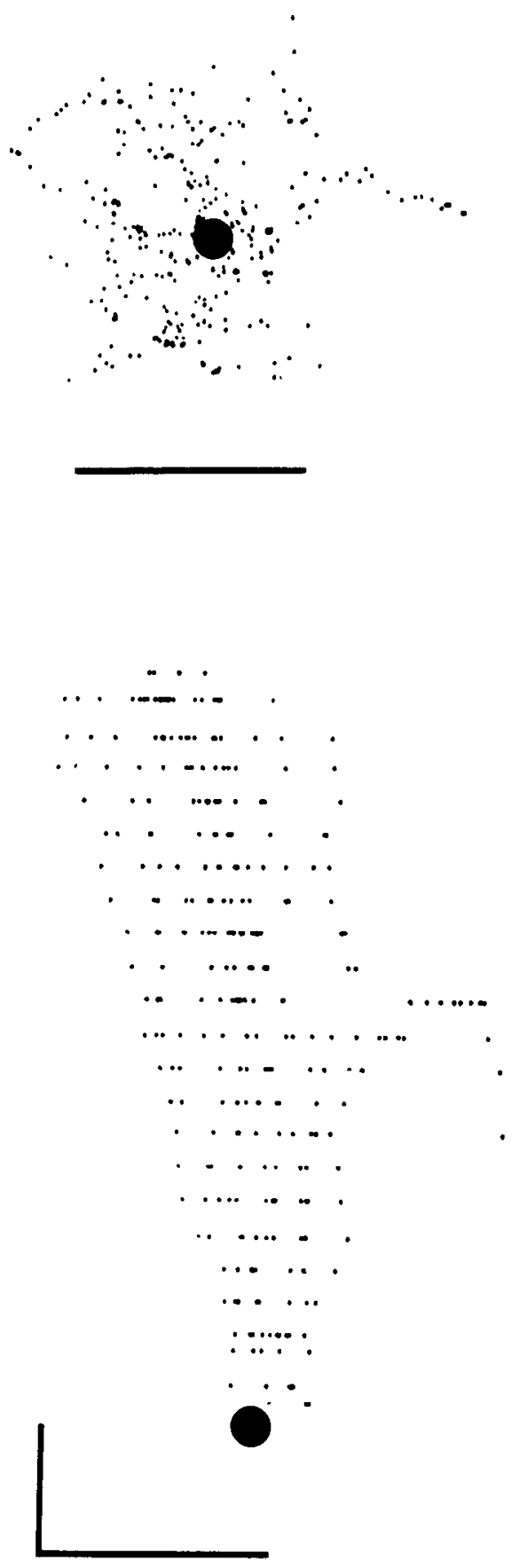

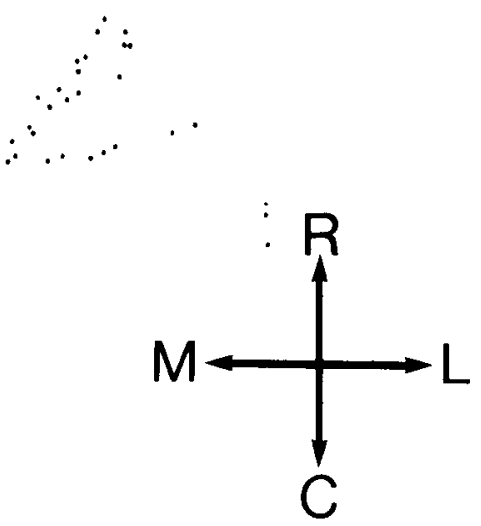

B

their arborizations. In the cell shown in Figure 13, the soma sat near a stripe border. Almost all the processes grew away from the border; a few traveled along it for some distance. When viewed coronally (Fig. 13B), the arbor was strongly biased away from the border. When the cell was viewed in the sagittal plane (Fig. 13C) (along a stripe, rather than across stripes), a rostral bias was evident, but the cell's structure did not suggest the presence of a border.

Occasionally an SD cell with 2 clumps of processes was observed. Two such cells, one from a normal and one from a striped tectum, are shown in Figures 14 and 15. In both cases, the arbor consisted of a larger parent arbor and a much smaller daughter arbor. A possible indication of the influence of stripes was the position of the daughter arbor. As the rotated, coronal view reveals (Fig. 15B), one of the cell's dendrites began branching and arborizing just at the point where it entered the next stripe. The branches of the daughter arbor remained completely confined to this stripe, while the parent arbor was confined to a different stripe.

\section{Rostral-caudal and medial-lateral cells}

The tangential extent and arbor density of the small deep cells represented one end of the morphological spectrum. At the other extreme were 2 categories of large cells: neurons whose dendrites branched infrequently but extended considerably along the tectum's rostral-caudal axis ( $\mathrm{RC}$ cells) and neurons with extensive medial-laterally oriented dendrites (ML cells). RC cells had medium-sized cell bodies (6-8 $\mu \mathrm{m}$ diameter) located in upper layer 

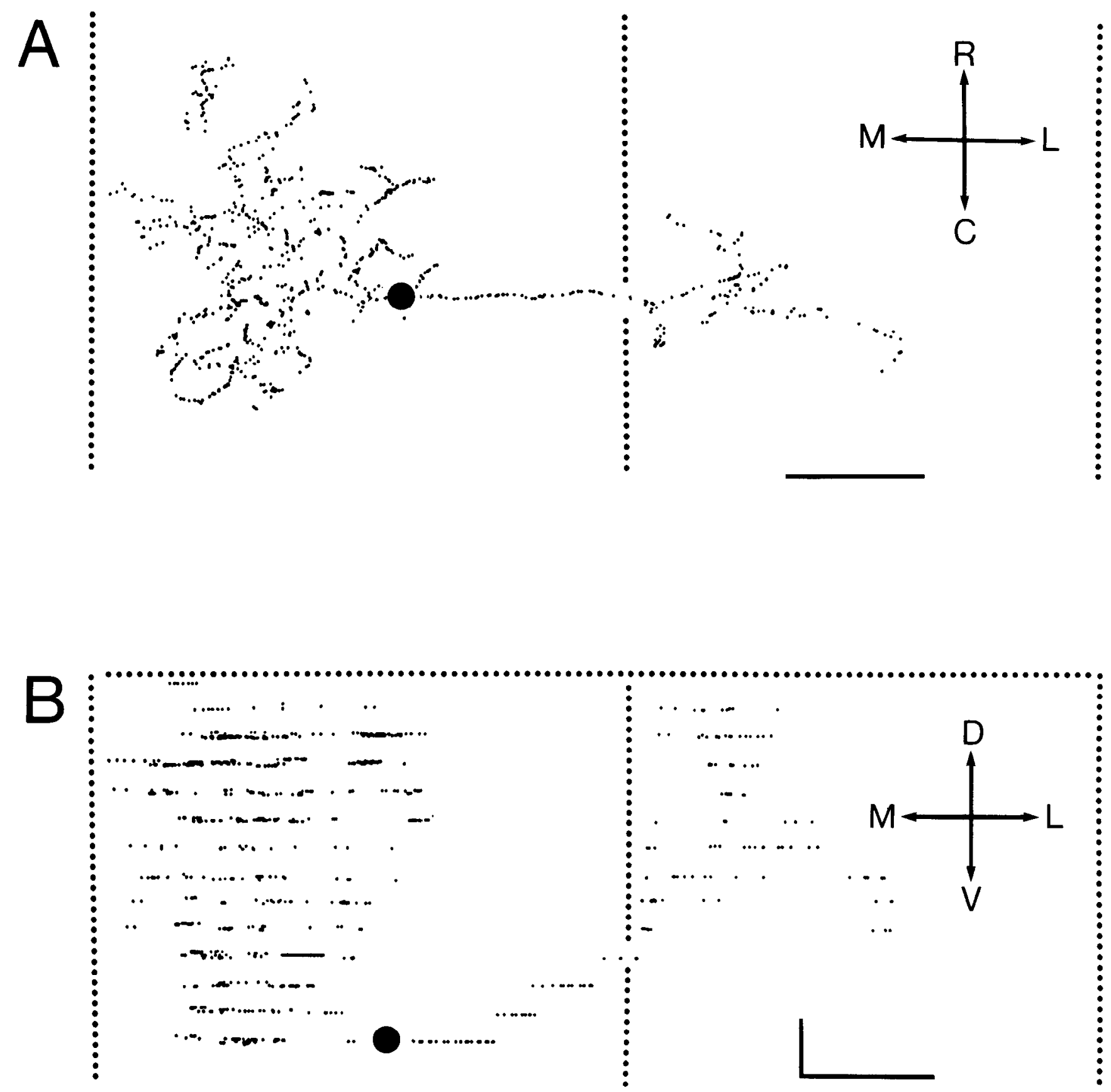

Figure 15. Dot-plot representation of a "clumped" SD cell from a striped tectum. This cell has its parent arbor within one eye's stripe, and the daughter arbor in a different eye's stripe. In the tangential view $(A)$, it appears that the daughter arbor develops only after one of the primary dendrites crosses a stripe boundary. The coronal view $(B)$ suggests that both parent and daughter arbors are constrained by stripe boundaries to remain within their respective eye termination zones. The behavior of these dendrites is similar to that of the SSC cells (Figs. 6-8). Scale bars: horizontal, $50 \mu \mathrm{m}$; vertical, $20 \mu \mathrm{m}$.

6,7 , or 8 of the tectum. Generally, 2 primary dendrites arose from opposite ends of the soma, and traveled rostrally and caudally at about the same depth as the soma. Finer processes emerged from these dendrites and rose through layer 9, occasionally producing small medial-laterally oriented processes. This arbor was restricted medial-laterally to between 1 and 2 stripe widths, whereas the rostral-caudal dendrites extended the equivalent of 3-6 stripe widths. The ratio of the length of rostralcaudal to medial-lateral dendritic extent was always greater than 2:1. ML cells were of similar cell body size and location, but the 2 primary dendrites ran medial-laterally, with secondary, finer branches arborizing rostral-caudally, in the more dorsal layers (Fig. 16). These probably correspond to multipolar cells of Potter (1969) and to some of the ganglionic neurons of Szekely and Lazar (1976). In striped tecta the primary branches frequently extended over 6-8 stripe widths, making them the cells with the largest arbors we encountered. In contrast, the smaller secondary dendrites were restricted to the equivalent of 2-3 stripe widths in the rostral-caudal direction (Fig. 17).

Both types of cells occurred with different frequencies in normal and striped tecta. In normal tecta, RC cells accounted for $15 \%$ of the sample, whereas in striped tecta, they accounted for 


\section{$m$}

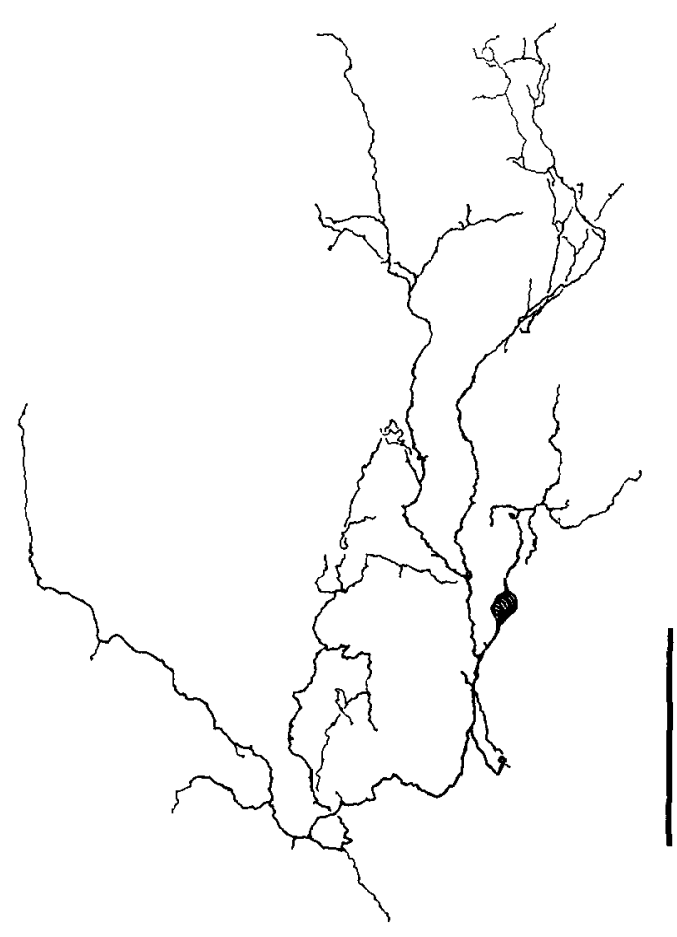

ํㅗ

䒿尝

콜

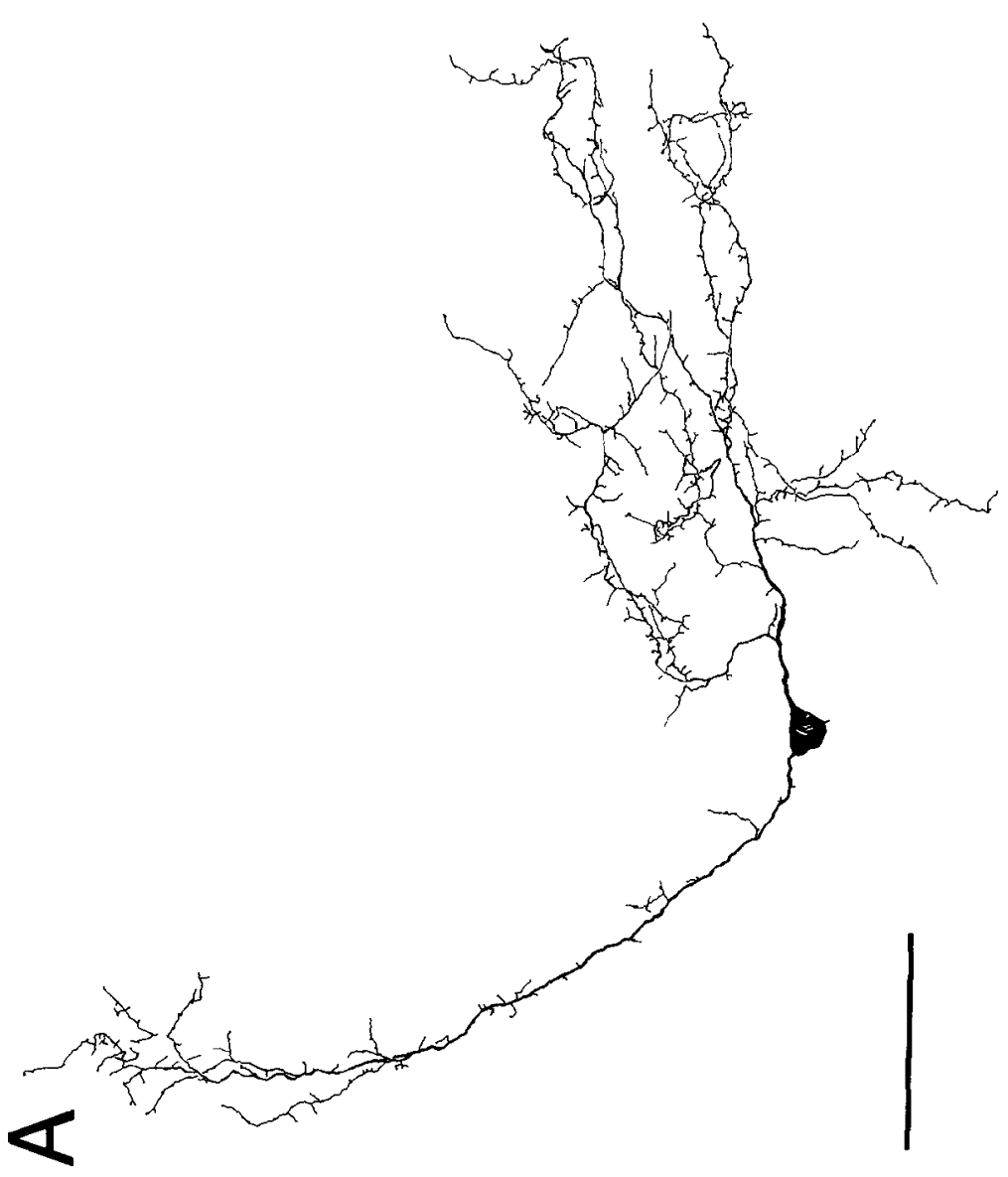

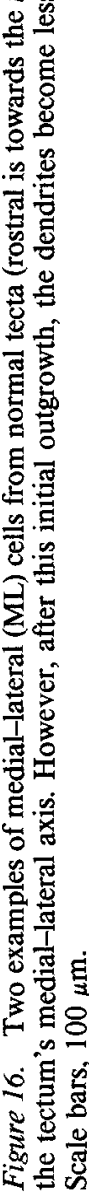



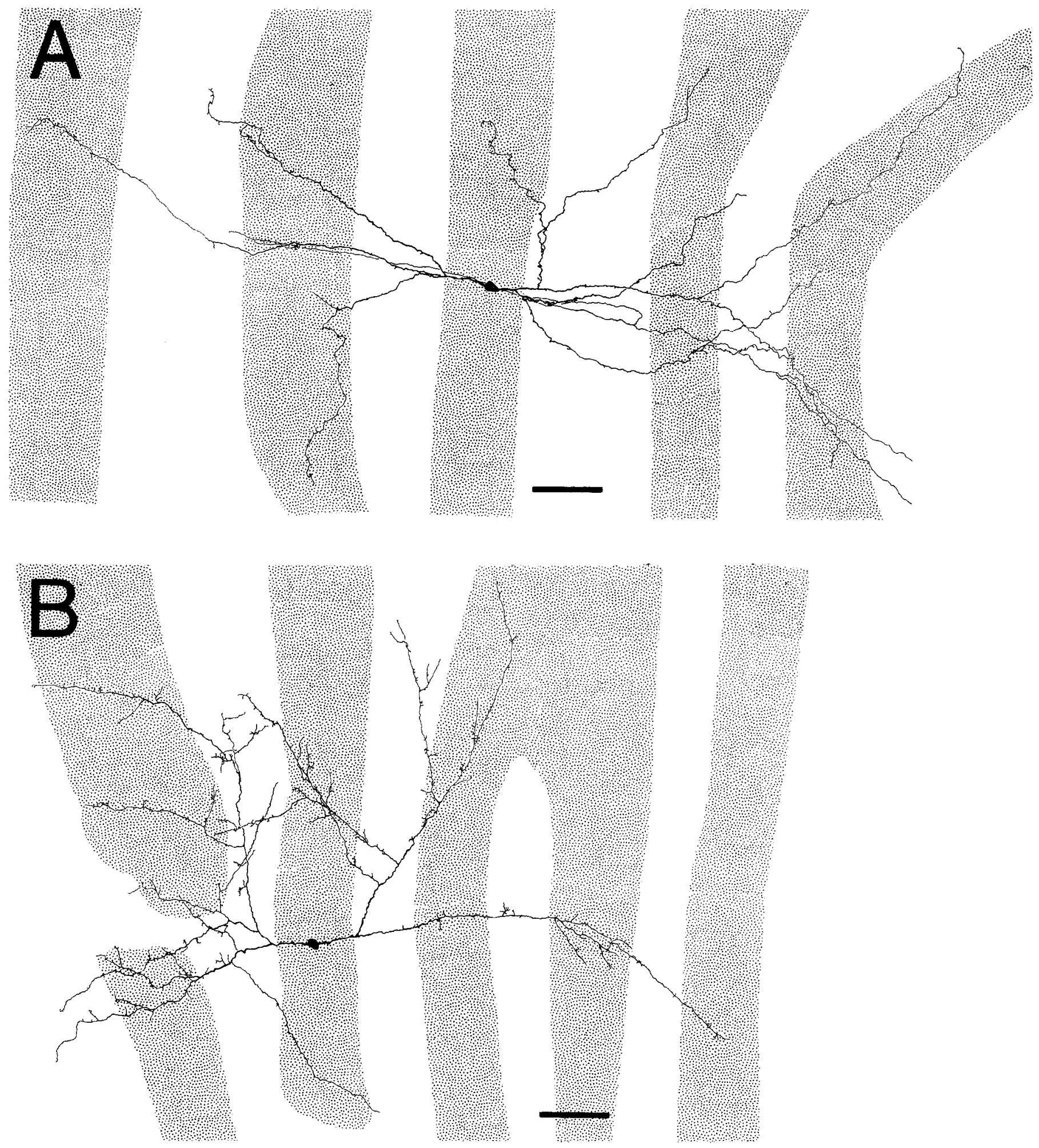

Figure 17. Two examples of ML cells from striped tecta. The 2 primary dendrites of these cells run almost perpendicular to the direction of the stripes. These cells are among the largest enountered in these experiments; their dendritic arbor covers over one-quarter of the tectum. The dendrites of these neurons do not respond to stripe boundaries in an obvious or predictable manner. Scale bars, $100 \mu \mathrm{m}$.

only $4 \%$ of filled cells. Additionally (although the numbers are too small for statistical analysis), the RC cells in striped tecta may be smaller than those in normal tecta. The largest of the 2 $\mathrm{RC}$ cells in striped tecta was only $60 \%$ the size of the largest $\mathrm{RC}$ cell in normal tecta, and the smaller RC cell in the striped tecta was smaller than any $\mathrm{RC}$ cell in the normal brain.
We encountered the opposite situation with ML neurons: cells in striped tecta had a considerably greater medial-lateral extent than those in normal animals. Six ML cells were encountered in striped tecta and 4 in normal tecta. Three of the $4 \mathrm{ML}$ cells in normal tecta had medial-lateral arbors equivalent to $1.5-2.5$ stripe widths, whereas the arbors of 4 out of $5 \mathrm{ML}$ cells in striped 
tecta covered greater than 6 stripe widths (compare Figs. 16 and 17). Even taking into account that doubly innervated tecta are approximately $40 \%$ larger than the singly innervated tecta (see Discussion), ML cells still appear to be almost twice as large in striped versus normal tecta. One cell in a normal tectum, tentatively identified as ML on the basis of the overall orientation of its major dendrites, had a very extensive medial-lateral arbor (greater than 6 stripe widths). However, this cell was unusual in that prior to arborizing medial-laterally, the 2 primary dendrites ran rostrocaudally for some distance. This behavior was not seen in any other ML cells in striped or normal tecta.

In addition to differences in size, ML cells in striped tecta differed from those in normal tecta in the relationship of their primary dendrites to the medial-lateral axis of the tectum. In striped tecta, ML cells had their primary dendrites oriented nearly orthogonal to the pattern of stripes, and they retained this orientation for considerable distances. Although ML cells in normal tecta were clearly oriented, their dendrites were neither perpendicular to the medial-lateral axis of the brain, nor parallel to each other.

ML cells in striped tecta were intriguing both because of the consistent orientation of their primary dendrites and because these processes could cover over half the medial-lateral extent of the tectum. This structure suggested that ML cells could be involved in dictating stripe periodicity if their secondary dendrites had selective association with the termination zones of only 1 eye. However, the relationship, if any, of the finer, secondary dendrites of ML cells to the pattern of the stripes is difficult to unravel, especially with our small sample size.

\section{Discussion}

The borders of both normal ocular dominance columns and induced tectal stripes represent transitions between regions within which afferent activity is temporally correlated and between which abrupt differences in activity patterns occur (Hubel and Weisel, 1965; Law and Constantine-Paton, 1981; Stryker and Strickland, 1984; Schmidt and Eisele, 1985; Rankin and Cook, 1986). The literature on tectal stripes further suggests that differences in activity patterns are the only functionally important difference between 2 sets of afferents (Constantine-Paton and Law, 1978; Law and Constantine-Paton, 1981; Fawcett and Willshaw, 1982; Ide et al., 1983). Consequently, in our analyses we have made several assumptions concerning the relationship between the afferent axons forming the stripes and the tectal neurons within them. First, we assume that the only retinal inputs to the tectum come from the contralateral and supernumerary eyes. The retinotectal projection of normal frogs is completely crossed, and normal binocular responses of neurons in frog tecta only begin at metamorphosis (Udin, 1985). A second assumption is that the functionally important characteristic of a boundary is an abrupt discontinuity in the pattern of action potentials carried by inputs located at closely adjacent points on the tectum. Within an individual stripe, action potentials in adjacent inputs should be relativcly correlated. We further assume that a dendrite's position within the superficial tectal neuropil accurately reflects the position of excitatory inputs driven by the retinal afferents to that region. Although no direct anatomical or physiological evidence supports this point, several lines of evidence sugest that for most superficial tectal neurons this assumption is valid. The dendritic arborizations we analyzed were located primarily within superficial laminae 8 and 9 , where most synaptic inputs originate from the retinal projection: eye removal reduces the number of synapses by approximately 60\% (Ostberg and Norden, 1979). These synapses are probably excitatory, since electron microscopic observations show that most retinotectal terminals contain round vesicles characteristic of excitatory synapses (Szekely and Lazar, 1976), and intracellular recordings indicate that most cells in the superficial layers have initial excitatory responses to retinal afferent stimulation (Matsumoto and Bando, 1980; McCrea and Grobstein, 1983; Antal et al., 1986; Matsumoto et al., 1986). These excitatory responses are either mono- or disynaptically mediated, and frequently followed by a long-latency IPSP. Neurons with initially hyperpolarizing responses to optic nerve stimulation have longer latencies ( $40 \mathrm{msec}$ or more) and are localized to layer 6 or deeper tectal laminae (McCrea and Grobstein, 1983). Finally, combined intracellular and HRP filling studies of homologous layers in the pigeon optic tectum reveal that all cells with dendrites arborizing in the retinorecipient layers receive excitatory input from retinal ganglion cells (Hardy et al., 1985).

\section{Segregation of dissimilar afferents onto different dendrites}

In striped tecta, dendrites appear to respond to stripc boundaries by either ending, branching, or perhaps turning toward the tectal surface. The first type of behavior-cells whose dendrites all terminate at stripe borders-produces cells whose markedly asymmetric dendritic fields abut a stripe boundary and avoid zones occupied by the other eye's afferents. These dendrites have no abrupt boundaries in the rostral-caudal domain.

The second type of behavior-branching at a stripe boundary -is observed primarily in SSC cells. These maintain a subset of dendrites in one stripe (the "home" stripe) and a separate subset in another stripe, indicating that cells can receive dissimilar inputs, if these inputs are segretated onto different dendrites. The position of the soma relative to a stripe boundary and the cell's inherent frequency of branching seem to determine whether a cells' arborization is segregated into individual stripes at the level of the primary, versus secondary, dendrites. If a cell has a small arbor, branches frequently, and is not immediately adjacent to a boundary, its dendrites generally remain confined to one zone (e.g., segregated primary dendrites). Cells with larger arbors, lower branching frequency, and close proximity to a border have separate termination zones sequestered onto different secondary branches (e.g., segregated secondary dendrites).

A third type of possible cellular response to boundaries, turning at a stripe boundary, is seen in cells whose dendrites branch even less frequently. These neurons, mostly "ganglionic" type cells, behave as if individual dendrites cannot easily exist deep in the neuropil of the other eye, but must also reach a certain size. If the dendrites of these cells exist in 2 eye termination zones, they are found at the top of the neuropil, beneath the pia.

Some cells in striped tecta, therefore, grow or have dendrites pruned in a pattern that reduces the mixing of dissimilar inputs on adjacent regions of a single dendrite's membrane. These observations apply to a significant fraction of the cells encountered in striped tecta. All members of the SS and SSC classes, representing $15 \%$ of our sample, showed what we consider strong evidence of response to stripes. Of the SD cells, all those large enough to encounter a stripe boundary -4 of 20 cells - showed similarly strong responses. Hence the "responding" cells represent roughly a quarter of our sample. Another quarter of the sample, consisting of large and small ganglionic cells, showed 
possible, but not unambiguous responses to stripes. One group, the ML cells, had dendrites that consistently grew across stripe boundaries with no evidence of discontinuities in their growth pattern. These cells had an exaggerated version of the mediallateral bias present in similar type cells of normal tecta and had primary dendrites running orthogonal to the stripes. In our limited sample, ML cells in striped tecta are larger than similar cells in normal tecta. Their response to stripes may be a more global change in the direction or amount of dendritic growth or pruning.

Dendritic alterations in striped tecta, then, are neither rare nor restricted to a single type of cell. They are also not universal, and the dendrites of many cells are not affected in an obvious way by the presence of stripes. Some tectal neurons therefore seem capable of detecting and responding to the presence of 2 temporally distinct afferent systems. Nevertheless, the pattern of afferent determination does not overridingly determine the shape of a dendritic arbor, nor does it appear to influence the disposition of all dendrites. This implies that other influences exist, and these may be as strong as that of the afferents. For instance, we do not know if the extent of influence may be related to the proportion of a cell's input that arose from the retina. It seems plausible that some cell types could receive a higher proportion of their input directly from retinal ganglion cells than other cells in the same layer, and thereby be most clearly influenced by the striping pattern.

\section{Dendritic segregation of dissimilar afferents: comparisons with other systems}

In only a few other regions have attempts been made to closely correlate a cell's dendritic morphology with position of its afferent inputs. For example, in differentiating autonomic ganglia the number of primary dendrites expressed by an immature neuron predicts how many different afferent fibers it eventually supports (Purves and Hume, 1981; Hume and Purves, 1981). As development proceeds, thesc cclls lose many initial inputs until the number of primary dendrites closely matches the number of functionally demonstrable inputs. In some ways each stripe in the doubly innervated tectum is analogous to the individual afferent fibers in the autonomic ganglion. Each stripe consists of groups of fibers arising from a very local region of the same retina and terminating in a restricted region of the tectum. If the tectum employs rules similar to autonomic ganglia, then the dendrites of tectal cells might normally be constructed so as to allow separate inputs, which in this experimental case would be inputs from each eye, to be placed on different dendrites. Although it is difficult to completely rule out this possibility of a preexisting cellular architecture around which stripes form, we think it an unlikely explanation for our results. No class of cells in normal tecta had consistent overall dendritic dimensions or arborization patterns that could generate the stereotyped width or repeat pattern of the stripes. Such cells would be expected in normal tecta if dendritic morphology was independent of the afferent segregation pattern. Also, the tendency of some tectal cells to form 2 separate clusters when confronting the stripe of another eye, which was rarely seen in normal tecta, suggested that cells respond to, rather than determine, stripe boundaries.

The different roles of dendrites and afferents in tectum and autonomic ganglion may reflect differences in the constraints on neuronal differentiation in these 2 systems. In general, developing CNS dendrites do seem labile and responsive to their afferent input. For example, in layer 4 of the barrel field of rodent somatosensory cortex, dendrites of individual post-synaptic cells segregate the incoming thalamocortical afferents carrying the activity from different vibrissae. The dendrites of cells whose somata form the "walls" of each barrel are highly asymmetric and directed towards the barrel center where they normally meet the thalamocortical afferents of only one vibrissa. Early damage to the periphery can alter this clear-cut dendritic organization. If a row of whiskers is removed, a large "barrel-like territory" (BLT) forms, which resembles one giant barrel. Some of the cells in the center of the BLT would have been on the sides of normal barrels, and thus have asymmetric dendrites. However, in the altered cortex, these cells have radially symmetric fields, which implies that the dendritic segregation results from, and is not an underlying cause of, the strict afferent segregation (Woolsey and Van der Loos, 1970; Harris and Woolsey, 1979; Steffen and Van der Loos, 1980).

Additional evidence for afferent modulation of dendritic shape has been found in the dendritic organization of primate layer 4 stellate cells. When ocular dominance columns were labeled in macaque monkeys, it was found that intracellularly stained neurons near borders had dendritic arbors that were biased away from column borders, much like the SD cells in the frog tectum. This was only true for cells within one dendritic radius of the border. Interestingly, cells almost exactly on the border between 2 columns had separate clumps of dendrites within each afferent termination zone, thereby resembling the SSC cells observed in the frog (Katz et al., 1986).

There is also a large literature in which selective sensory deprivation or deafferentation has been used to determine afferent effects on dendritic morphology (see Globus, 1975, for review). Observations of atrophy in only parts of deafferented dendritic fields suggests both a dependence of dendrites on their inputs and autonomy of individual dendrites in their response to deprivation (e.g., Murphey et al. 1975; Sotelo and Arsenio-Nunes, 1976; Rubel et al., 1981; Caceres and Steward, 1983; Deitch and Rubel, 1984). However, these studies cannot dissociate the effects of loss of specific activity patterns from consequences of the loss of trophic support. Studies demonstrating increased dendritic proliferation with "enriched" environments overcome the latter objection, but the primary locus of such effects has been difficult to ascertain (e.g., Greenough et al., 1973). Thus, the extent to which afferent activity patterns influence dendritic form remains unknown for most types of neurons.

Although we did not observe the early developmental events in the frog optic tectum, there appears to be both fixed and afferent-induced components to the final form of a dendritic tree. Despite the pronounced disruption of their normally continuous retinal input, neurons in striped tecta are recognizable as common tectal types and resemble their counterparts in normal tecta in soma size and depth and in the general orientation, caliber, and branching pattern of dendrites. These properties are probably fixed at the time a cell begins differentiating. Exactly which dendrites grow fastest, where they branch, and where they might be pruned is probably influenced by afferent inputs. This general idea has been suggested previously (see, e.g., Caviness and Rakic, 1978; Berry, 1982).

However, we hypothesize that the degree of correlation in the afferent activity, not simply the presence of afferents themselves, can modulate the growth of a tectal neuron's dendrites. Thus, we propose the dendritic responses observed in striped tecta result from the sudden shift in retinal activity patterns at stripe 
borders, with the shifts effectively decreasing or deflecting dendritic growth or removing inappropriately situated branches. These responses could result from active inhibition of dendritic growth or selective dendritic pruning by noncorrelated inputs or by the selective facilitation of the growth of those dendrites encountering correlated activity. In other systems, dendrites can extend beyond their normal territories towards regions of available afferent input, implying the existence of selective growth facilitation (Valverde, 1968; Perry and Linden, 1982; Hoy et al., 1984; Eysel et al, 1985).

We have no evidence from developing tectal cells about the relative roles of inhibition, pruning, and selective growth. However, a positive growth response to correlated inputs could account for the preponderance of rostrally, as opposed to caudally, biased dendritic trees in normal tecta, and their significant decrease upon double innervation. These patterns of dendritic bias could arise because most tectal neurons receive 2 distinct sets of inputs during the initial stages of retinotectal synaptogenesis: one set emerging from the already established rostral region of tectum and one newly invading set entering from the tectum's caudal boundary. During normal development, more tectal dendritic sprouts might grow robustly in rostral tectum, where afferent density is higher. Rostral inputs, which have been in the tectum longer and have had more time to establish their correct topographic positions, would be expected to carry more correlated information within a unit of neuropil, compared with the newer, sparser, less refined caudal inputs.

Since in striped tecta nearly twice as many retinal ganglion cells arborize within a tectal neuropil whose volume increases only 40\% (Constantine-Paton and Ferrari-Eastman, 1987), each portion of neuropil in striped tecta receives input from many more retinal ganglion cells than the same volume in a normal tcctum would. This could saturate innervation in established tectal regions and bring innervation levels to a much higher level in caudal tectum. Thus cells with a rostral bias based on afferent innervation density could be reduced, and this could produce the greater proportion of unbiased cells observed in striped tecta.

\section{Competition and proposed effects of correlated activity}

Studies in numerous developing systems implicate competition between afferent terminals as a major factor in structuring the pattern of mature connections. The stripes in double-innervated frog tectum, like the induced segregation in goldfish and normal ocular dominance columns of cats and primates, reflect a competitive balance between the inputs from 2 eyes (LeVay et al., 1975; Shatz and Stryker, 1978; Constantine-Paton, 1981). In all of these systems, competition requires presynaptic action potentials (Meyer, 1982; Boss and Schmidt, 1984; Reh and Constantine-Paton, 1985; Stryker and Harris, 1986), and although postsynaptic cells are probably involved, their precise role remains obscure (Hubel and Wiesel, 1965; Guillery, 1972; Constantine-Paton and Norden, 1986; Reiter et al., 1986; Constantine-Paton and Ferrari-Eastman, 1987). In particular, it is not known whether action potentials are required both pre- and postsynaptically or whether local postsynaptic potentials alone can drive presynaptic terminals from an overlapping to a segregated state. Most current models of afferent competition (Stent, 1973; Changeux and Danchin, 1976; Von der Malsberg and Willshaw, 1976; Fraser, 1980; Swindale, 1980; Whitelaw and Cowan, 1981; Miller et al., 1986) are based, at last in part, on the initial formulation of Hebb (1949). In these models, con- nections between pre- and postsynaptic cells are enhanced if the presynaptic terminals excite the postsynaptic cell sufficiently to evoke an action potential. The close temporal proximity of the pre- and postsynaptic action potentials strengthens that connection, while synapses whose activity is not correlated with that of the postsynaptic cell are weakened and eventually eliminated. Thus, in strictly Hebbian models, the postsynaptic membrane must be pushed to its spike threshold. Local synaptic potentials are not sufficient to produce the selective reinforcement (Hebb, 1949).

Morphological analyses alone cannot distinguish between a requirement for postsynaptic action potentials or for temporal summation of local events. Nevertheless, the shape of a cell's dendritic tree relative to zones of afferents known to have correlations in activity can help differentiate between these 2 possibilities. In strict Hebbian models the entire cell should act in concert and maintain all of its arbor within a single zone since an action potential is likely to depolarize all of the cell's postsynaptic surface.

Our observations demonstrate that many tectal neurons can, when confronted with a boundary, assign portions of their dendritic arbors to 2 zones of temporally disparate activity. The segregation occurs at the level of primary or secondary dendritic branches, suggesting that these structures, and not the entire cell, are the units of postsynaptic integration. This result is interesting in light of recent evidence for a possible molecular mechanism for intraocular afferent segregation, based on the properties of the $N$-methyl-D-aspartate (NMDA) glutamate receptor (Singer et al., 1986; Rauschecker and Hahn, 1987). The retinotectal projection in frogs and goldfish is apparently glutaminergic (Langdon and Freeman, 1986; Debski et al., 1987). Blocking the NMDA receptors results in complete, reversible desegregation of frog tectal stripes (Cline et al., 1987). The data on NMDA channel physiology and pharmacology indicate that this channel could mediate competition in local regions of the postsynaptic membrane (see, e.g., MacDermott and Dale, 1987).

Our observations that single tectal dendrites can function as autonomous postsynaptic detectors of correlated afferents are consistent with the proposed role for the NMDA conductance. Depolarization of a single dendrite by activity in a subset of converging synapses would allow glutamate to activate the conductance within a restricted domain of the postsynaptic cell. This could, in turn, provide cues for stabilizing and enlarging a small portion of the dendritic arbor, independent of the behavior of other dendrites.

\section{References}

Antal, M., N. Matsumoto, and G. Szekely (1986) Tectal neurons of the frog: Intracellular recording and labeling with cobalt electrodes. J. Comp. Neurol. 246: 238-253.

Berry, M. (1982) Cellular differentiation: Development of dendritic arborizations under normal and experimentally altered conditions. In Development and Modifiability of the Cerebral Cortex, Neurosci. Res. Prog. Bull. 20: 451-461.

Boss, V. C., and J. T. Schmidt (1984) Activity and the formation of ocular dominance patches in dually innervated tectum of goldfish. $\mathrm{J}$. Neurosci. 4: 2891-2905.

Caceres, A., and O. Steward (1983) Dendritic reorganization in the denervated dentate gyrus of the rat following entorhinal cortical lesions: A Golgi and electron microscopic analysis. J. Comp. Neurol. 214: 387-403.

Caviness, V. S., Jr., and P. Rakic (1978) Mechanisms of cortical development: A view from mutations in mice. Annu. Rev. Neurosci. 1: $297-326$. 
Changeux, J. D., and A. Danchin (1976) Selective stabilization of developing synapses as a mechanism for the specification of neuronal networks. Nature 264: 705-712.

Cline, H. T., E. Debski, and M. Constantine-Paton (1987) N-Methyl$D$-aspartate receptor antagonist desegregates eye-specific stripes. Proc Natl. Acad. Sci. USA 84: 4342-4345.

Constantine-Paton, M. (1981) Induced ocular-dominance zones in tectal cortex. In The Organization of the Cerebral Cortex, F. O. Schmitt, F. G. Worden, G. Adelman, and S. G. Dennis, eds., pp. 47-67, MIT Press, Cambridge, MA

Constantine-Paton, M., and P. Ferrari-Eastman (1987) Pre- and postsynaptic correlates of interocular competition in the frog. J. Comp. Neurol. 255: 178-195.

Constantine-Paton, M., and M. I. Law (1978) Eye-specific termination bands in tecta of three-eyed frogs. Science 202: 639-641.

Constantine-Paton, M., and J. I. Norden (1986) Synapse regulation in the developing visual system. In Cell and Developmental Biology of the Eye, Vol. 5, S. R. Hilfer and J. Sheffield, eds., pp. 1-14, SpringerVerlag, New York.

Currie, J., and W. M. Cowan (1974) Some observations on the early development of the optic tectum in the frog Rana pipiens with special reference to the effects of early eye removal on mitotic activity in the larval tectum. J. Comp. Neurol. 156: 123-142.

Debski, E. A., H. T. Cline, and M. Constantine-Paton (1987) Kynurenic acid blocks retino-tectal transmission in Rana pipiens. Proc. Soc. Neurosci. 13: 1691.

Deitch, J. S., and E. W. Rubel (1984) Afferent influences on brain stem auditory nuclei of the chicken: Time course and specificity of dendritic atrophy following deafferentation. J. Comp. Neurol. 229: 66-79.

Eysel, U. T., L. Peichle, and H. Wassle (1985) Dendritic plasticity in the early postnatal feline retina: Quantitative characteristics and sensitive period. J. Comp. Neurol. 242: 134-145.

Fawcett, J. W., and D. G. Willshaw (1982) Compound eyes project stripes on the optic tectum in Xenopus. Nature 296: 350-352.

Fraser, S. E. (1980) A differential adhesion approach to the patterning of nerve connections. Dev. Biol. 79: 453-464.

Gaze, R. M., M. J. Keating, A. Ostberg, and S. H. Chung (1979) The relationship between retinal and tectal growth in larval Xenopus. Implication for the development of the retinotectal projection. J. Embryol. Exp. Morphol. 53: 103-143.

Gilbert, C. D., and T. N. Wiesel (1983) Clustered intrinsic connections in cat visual cortex. J. Neurosci. 3: 1116-1133.

Globus, A. (1975) Brain morphology as a function of presynaptic morphology and activity. In Developmental Neuropsychology of Sensory Deprivation, A. H. Rieser, ed., pp. 9-91, Academic, New York.

Greenough, W. T., F. R. Volkmar, and J. M. Juraska (1973) Effects of rearing complexity on dendritic branching in frontolateral and temporal cortex of the rat. Exp. Neurol. 41: 371-378.

Guillery, R. W. (1972) Binocular competition in the control of geniculate cell growth. J. Comp. Neurol. 144: 177-230.

Hardy, O., N. Leresche, and D. Jussik-Gershenfeld (1985) Morphology and laminar distribution of electrophysiologically identified cells in the pigeon optic tectum: An intracellular study. J. Comp. Neurol. 233: $390-404$

Harris, R. M., and T. A. Woolsey (1979) Morphology of Golgi-impregnated neurons in mouse cortical barrels following vibrissae damage at different post-natal ages. Brain Res. 161: 143-149.

Hebb, D. O. (1949) The Organization of Behavior, Wiley, New York.

Hoy, R. R., T. G. Nolan, and G. C. Casady (1984) Dendritic sprouting and compensatory synaptogenesis in an identified interneuron following auditory deprivation in a cricket. Proc. Natl. Acad. Sci. USA 22: 7772-7776.

Hubel, D. H., and T. N. Wiesel (1965) Binocular interaction in striate cortex of kittens reared with artificial squint. J. Neurophysiol. 28: 1041-1059.

Hume, R. I., and D. Purves (1981) Geometry of neonatal neurones and the regulation of synapse elimination. Nature 293: 469-471.

Ide, C. F., S. E. Fraser, and R. L. Meyer (1983) Eye dominance columns from an isogenic double-nasal frog eye. Science 221: 293-295.

Katz, L. C. (1987) Local circuitry of identified projection neurons in cat visual cortex brain slices. J. Neurosci. 7: 1223-1249.

Katz, L. C., and M. Constantine-Paton (1985) Afferent induced alterations in the dendritic domains of tectal neurons in three-eyed frogs. Proc. Soc. Neurosci. 11: 804.
Katz, L. C., C. D. Gilbert, and T. N. Wiesel (1986) Local circuits and ocular dominance columns in monkey striate cortex. Proc. Soc. Neurosci. 12: 1498.

Langdon, R. B., and J. A. Freeman (1986) Antagonists of glutaminergic neurotransmission block retinotectal transmission in goldfish. Brain Res. 398: 169-174.

Law, M. L., and M. Constantine-Paton (1981) Anatomy and physiology of experimentally produced striped tecta. J. Neurosci. 1:741759.

Lazar, G. (1973) The development of the optic tectum in Xenopus laevis: A Golgi study. J. Anat. 116: 347-335.

Lazar, G., P. Toth, G. Csank, and E. Kicliter (1983) Morphology and location of the tectal projection neurons in frogs: A study with HRP and cobalt-filling. J. Comp. Neurol. 215: 108-120.

LeVay, S., D. H. Hubel, and T. N. Wiesel (1975) The pattern of ocular dominance columns in macaque visual cortex revealed by a reduced silver stain. J. Comp. Neurol. 159: 559-576.

LeVay, S., T. N. Wiesel, and D. H. Hubel (1980) The development of ocular dominance columns in normal and visually deprived monkeys. J. Comp. Neurol. 191: 1-51.

MacDermott, A. B., and N. Dale (1987) Receptors, ion channels, and synaptic potentials underlying the integrative actions of excitatory amino acids. Trends Neurosci. 10: 280-284.

Matsumoto, N., and T. Bando (1980) Excitatory synaptic potentials and morphological classification of tectal neurons of the frog. Brain Res. 192: 39-48

Matsumoto, N., W. W. Schwippert, and J.-P. Ewert (1986) Intracellular activity of morphologically identified neurons of the grass frog's optic tectum in response to moving configurational visual stimuli. J. Comp. Physiol. A 159: 721-739.

McCrea, R. A., and P. Grobstein (1983) Anatomical and physiological characteristics of the neurons in the frog optic tectum receiving optic input. Proc. Soc. Neurosci. 9: 818.

Meyer, R. L. (1982) Tetrodotoxin blocks the formation of ocular dominance columns in goldfish. Science 218: 589-591.

Miller, K. D., J. B. Keller, and M. P. Stryker (1986) Models for the formation of ocular dominance columns solved by linear stability analysis. Proc. Soc. Neurosci. 12: 1373.

Murphey, R. K., B. Mendenhall, J. Palka, and J. S. Edwards (1975) Deafferentation slows the growth of specific dendrites of identified giant intcrncurons. J. Comp. Neurol. 159: 407-418.

Ostberg, A., and J. J. Norden (1979) Ultrastructural study of degeneration and regeneration in the amphibian tectum. Brain Res. 168 . $441-455$.

Perry, D. H., and R. Linden (1982) Evidence for dendritic competition in the developing retina. Nature 297: 683-685.

Potter, H. D. (1969) Structural characteristics of cell and fiber populations in the optic tectum of the frog (Rana catesbiana). J. Comp. Neurol. 136: 203-232.

Purves, D., and R. I. Hume (1981) The relation of postsynaptic geometry to the number of presynaptic neurones that innervate autonomic ganglion cells. J. Neurosci. 1: 441-452.

Rankin, E. C. C., and J. E. Cook (1986) Topographic refinement of the regenerating retinotectal projection in goldfish in standard laboratory conditions: A quantitative WGA-HRP study. Exp. Brain Res. 63: $409-420$.

Rauschecker, J. P., and S. Hahn (1987) Ketamine-xylazine anaesthesia blocks consolidation of ocular dominance changes in kitten visua cortex. Nature 326: 183-185.

Reh, T. A., and M. Constantine-Paton (1985) Eye-specific segregation requires neural activity in three-eyed Rana pipiens. J. Neurosci. 5 : $1132-1143$

Reiter, H. O., D. M. Waitzman, and M. P. Stryker (1986) Cortical activity blockade prevents ocular dominance plasticity in kitten visual cortex. Exp. Brain Res. 65: 182-188.

Rubel, E. W., Z. D. J. Smith, and O. Steward (1981) Sprouting in the avian brain stem auditory pathway: Dependence on dendritic integrity. J. Comp. Neurol. 202: 397-414.

Schmidt, J. T., and L. E. Eisele (1985) Stroboscopic illumination and dark-rearing block the sharpening of the regenerated retinotectal map in goldfish. Neuroscience 14: 535-546.

Shatz, C. J., and M. P. Stryker (1978) Ocular dominance in layer IV of the cat's visual cortex and the effects of monocular deprivation. $J$. Physiol. (Lond.) 281: 267-283.

Singer, W., A. Kleinschmidt, and M. F. Bear (1986) Infusion of an 
NMDA receptor antagonist disrupts ocular dominance plasticity in kitten striate cortex. Proc. Soc. Neurosci. 12: 786.

Sotelo, C., and M. L. Arsenio-Nunes (1976) Development of Purkinje cells in the absence of climbing fibers. Brain Res. 111: 389-395.

Steffen, H., and H. Van der Loos (1980) Early lesions of mouse vibrissal follicles: Their influence on dendrite orientation in the cortical barrelfield. Exp. Brain Res. 40: 410-431.

Stent, G. S. (1973) A physiological mechanism for Hebb's postulate of learning. Proc. Natl. Acad. Sci. USA 70: 997-1001.

Stryker, M. P., and W. A. Harris (1986) Binocular impulse blockade prevents the formation of ocular dominance columns in cat visual cortex. J. Neurosci. 6: 2117-2133.

Stryker, M. P., and S. L. Strickland (1984) Physiological segregation of ocular dominance columns depends on the pattern of afferent electrical activity. Invest. Ophthalmol. Suppl. 25: 278.

Swindale, N. V. (1980) A model for the formation of ocular dominance stripes. Proc. R. Soc. London [Biol.] 208: 243-264.

Szckely, G., and G. Lazar (1976) Cellular and synaptic architecture of the optic tectum. In Frog Neurobiology, R. Llinás and W. Precht, eds., pp. 407-434, Springer-Verlag, New York.
Thanos, S., and F. Bonhoeffer (1983) Investigations on the development and topographic order of retinotectal axons: Anterograde and retrograde staining of axons and perikarya with rhodamine in vivo. J. Comp. Neurol. 219: 420-430.

Udin, S. (1985) The role of visual experience in the formation of binocular projections in frogs. Cell. Mol. Neurobiol. 5: 85-102.

Valverde, F. (1968) Structural changes in the area striata of the mouse after enucleation. Exp. Brain Res. 5: 274-292.

Von der Malsburg, C., and D. J. Willshaw (1976) Mechanism for producing continuous neural mappings: Ocular dominance stripes and ordinal retinotectal projections. Exp. Brain Res. (Suppl.) 1: 463469.

Whitelaw, V. A., and J. D. Cowan (1981) Specificity and plasticity of retinotectal connections: A computational model. J. Neurosci. 1: 13691387.

Woolsey, T. A., and H. Van der Loos (1970) The structural organization of layer IV in the somatosensory region (SI) of mouse cerebral cortex. The description of a cortical field composed of discrete cytoarchitectonic units. Brain Res. 17: 205-242. 